\title{
Energetics of surface melt in West Antarctica
}

\author{
Madison L. Ghiz ${ }^{1}$, Ryan C. Scott ${ }^{2}$, Andrew M. Vogelmann ${ }^{3}$, Jan T. M. Lenaerts ${ }^{4}$, Matthew Lazzara ${ }^{5,6}$, and \\ Dan Lubin ${ }^{1}$ \\ ${ }^{1}$ Scripps Institution of Oceanography, University of California San Diego, La Jolla, CA 92093-0206, USA \\ ${ }^{2}$ Science Systems and Applications, Inc., Hampton, VA 23666, USA \\ ${ }^{3}$ Environmental and Climate Sciences Department, Brookhaven National Laboratory, Upton, NY 11973-5000, USA \\ ${ }^{4}$ Department of Atmospheric and Oceanic Sciences, University of Colorado Boulder, Boulder, CO 80309-0311, USA \\ ${ }^{5}$ Antarctic Meteorological Research Center, Space Science and Engineering Center, \\ University of Wisconsin-Madison, Madison, WI 53706, USA \\ ${ }^{6}$ Madison Area Technical College, Madison, WI 53704, USA
}

Correspondence: Dan Lubin (dlubin@ucsd.edu)

Received: 20 October 2020 - Discussion started: 28 October 2020

Revised: 20 May 2021 - Accepted: 1 June 2021 - Published: 26 July 2021

\begin{abstract}
We use reanalysis data and satellite remote sensing of cloud properties to examine how meteorological conditions alter the surface energy balance to cause surface melt that is detectable in satellite passive microwave imagery over West Antarctica. This analysis can detect each of the three primary mechanisms for inducing surface melt at a specific location: thermal blanketing involving sensible heat flux and/or longwave heating by optically thick cloud cover, allwave radiative enhancement by optically thin cloud cover, and föhn winds. We examine case studies over Pine Island and Thwaites glaciers, which are of interest for ice shelf and ice sheet stability, and over Siple Dome, which is more readily accessible for field work. During January 2015 over Siple Dome we identified a melt event whose origin is an allwave radiative enhancement by optically thin clouds. During December 2011 over Pine Island and Thwaites glaciers, we identified a melt event caused mainly by thermal blanketing from optically thick clouds. Over Siple Dome, those same 2011 synoptic conditions yielded a thermal-blanketingdriven melt event that was initiated by an impulse of sensible heat flux and then prolonged by cloud longwave heating. The December 2011 synoptic conditions also generated föhn winds at a location on the Ross Ice Shelf adjacent to the Transantarctic Mountains, and we analyze this case with additional support from automatic weather station data. In contrast, a late-summer thermal blanketing period over Pine Island and Thwaites glaciers during February 2013 showed surface melt initiated by cloud longwave heating and then
\end{abstract}

prolonged by enhanced sensible heat flux. One limitation thus far with this type of analysis involves uncertainties in the cloud optical properties. Nevertheless, with improvements this type of analysis can enable quantitative prediction of atmospheric stress on the vulnerable Antarctic ice shelves in a steadily warming climate.

\section{Introduction}

The contribution of West Antarctic mass loss to sea level rise, presently the second largest cryospheric contribution to sea level rise after the Greenland Ice Sheet (Mouginot et al., 2019; Rignot et al., 2019), is driven by a complex mechanical and thermodynamic system involving grounded ice sheets, their floating ice shelf extensions, and the surrounding ocean and atmosphere. While a warming ocean causes a retreat of West Antarctic Ice Sheet grounding lines on numerous reverse slopes, by gradually accelerating the ice sheet outflow via the well-known marine ice sheet instability (Weertman, 1974; Oppenheimer, 1998; Joughin et al., 2014; Alley et al., 2015), the ice shelves mitigate this outflow through the buttressing they provide by being in contact with adjacent land masses (Fürst et al., 2016). But the ice shelves are themselves thinning via basal melting from the warming ocean (Pritchard et al., 2012; Paolo et al., 2015), which compromises their buttressing strength and also enhances the overall meltwater loss of Antarctic glacial ice (Adusumilli et al., 
2020). Structural integrity of an ice shelf can be further compromised when surface meltwater filters through crevasses into its interior mass, rendering the extremities more vulnerable to wave action (DeConto and Pollard, 2016; Bell et al., 2018). Extensive summer melt ponds occurring in a warming atmosphere were the major factor in the loss of the Larsen B Ice Shelf in 2002 (Scambos et al., 2003; van den Broeke, 2005; Glasser and Scambos, 2008). The loss of this ice shelf immediately facilitated faster ice calving of the upstream glaciers (Scambos et al., 2004). In 2008 similar ice shelf failures occurred on the Wilkins Ice Shelf, at the base of the Antarctic Peninsula near West Antarctica proper (Scambos et al., 2009). Surface and lower tropospheric warming are now understood to prevail throughout West Antarctica and across the Ross Ice Shelf (RIS) as far as Ross Island (Steig et al., 2009; Bromwich et al., 2013). Lhermitte et al. (2020) report satellite observational evidence of a corresponding ice shelf structural weakening in the Pine Island and Thwaites Glacier region of West Antarctica over the past decade.

Remote sensing studies now document frequent warmseason surface melting over West Antarctica and the Ross Ice Shelf (e.g., Kingslake et al., 2017). The energetics of a major melt event over West Antarctica during January 2016 were measured with modern atmospheric science equipment during the joint US Antarctic Program and Department of Energy Atmospheric Radiation Measurement (ARM) user facility's West Antarctic Radiation Experiment (AWARE; Nicolas et al., 2017; Lubin et al., 2020). These measurements provided insight into the role of atmospheric thermodynamics and cloud radiative properties in generating local surface melt. But in contrast to the Antarctic Peninsula and Greenland Ice Sheet, West Antarctic melt events tend to be shorter in duration and exhibit greater spatial, interannual, and intraseasonal variability. Remote sensing assessment of their total meltwater equivalent (e.g., Kuipers Munneke et al., 2012a), which is much smaller than that of basal melting, can give the impression that surface melt might not be an important consideration. But the potential for West Antarctic surface melt to aggravate ice mass loss involves structural degradation of ice shelves through ponding and hydrofracturing, as has already happened throughout much of the Antarctic Peninsula region. Recent studies of Antarctic ice mass balance now account for spatial and temporal variability on multiple scales (Lenaerts et al., 2018; Donat-Magnin et al., 2020; Adusumilli et al., 2020). When evaluating the potential impact of surface melt in West Antarctica, one should focus on assessing the frequency and duration of melt events directly on the vulnerable ice shelves and also on determining the specific physical mechanisms causing each melt event.

The objective of this work is to determine if readily available satellite remote sensing and meteorological reanalysis data can be used to identify the mechanisms that drive specific Antarctic surface melt events: thermal blanketing involving sensible heat flux and/or longwave heating by optically thick cloud cover, all-wave radiative enhancement by optically thin cloud cover, and föhn winds. Scott et al. (2019) identify the large-scale meteorological drivers of West Antarctic surface melt, and the approach presented here considers their application to specific locations using available satellite and surface data. If successful, then this approach can be used to assess future risk to the vulnerable West Antarctic ice shelves. For example, if melt events occur frequently under common polar meteorological phenomena such as optically thin clouds that produce the all-wave radiative enhancement, then the stress on the ice shelves might be perennially constant. Conversely, if melt events occur mainly under optically thick clouds only associated with strong atmospheric rivers (e.g., Wille et al., 2019), then one might expect more of a long-term risk in a warming atmosphere. Ultimately multi-year assessment of melt event mechanisms would need to be understood in terms of the large-scale meteorological drivers (Scott et al., 2019) to make such a risk assessment. Here we demonstrate with case studies that each of the above three melt-inducing mechanisms can be identified in satellite and reanalysis data.

\section{Data and methods}

Over the cryosphere the surface energy balance (SEB) can be expressed in terms of the melt energy $\mathrm{ME}\left(\mathrm{W} \mathrm{m}^{-2}\right)$ :

$\mathrm{ME}=F_{\mathrm{SW}}^{\downarrow}-F_{\mathrm{SW}}^{\uparrow}+F_{\mathrm{LW}}^{\downarrow}-F_{\mathrm{LW}}^{\uparrow}+F_{\mathrm{SH}}+F_{\mathrm{LH}}-G$,

where the individual energy components are the downwelling and upwelling shortwave (SW) and longwave (LW) radiation, the sensible heat flux $(\mathrm{SH})$, the latent heat flux (LH), and the ground conduction $G$. The sum of the four SW and LW fluxes is the net radiation. The sum of SH and LH fluxes is the net turbulent flux, and here we use the European Centre for Medium-Range Weather Forecasts (ECMWF) convention where a positive sign signifies energy going into the surface. Advection of air warmer than $0^{\circ} \mathrm{C}$ appears in the ME as positive SH flux, whose magnitude depends on both the air temperature gradient and the wind speed. Strictly speaking Eq. (1) is valid when the snow surface temperature $T_{\mathrm{S}}$ is at or above the melt point. If $T_{\mathrm{S}}$ is below the melt point and the SEB does not close (i.e., the net radiation is not balanced by the sum of the other energy components), it is likely due to ground conduction. Local radiative heating of a snowpack can induce melt at temperatures as low as $-2{ }^{\circ} \mathrm{C}$ by internal scattering and absorption (e.g., Nicolas et al., 2017). If $T_{\mathrm{S}}$ is at or above freezing, a positive ME maintains surface melting, while a negative ME represents a surface cooling that if sustained will reduce the surface temperature below freezing. A negative ME also represents a phase change (i.e., refreezing of the surface) if the $T_{\mathrm{S}}$ is at the melt point. The actual cooling happens through LW radiation and ground conduction. On daily timescales, $G$ over Antarctic firn is usually an order of magnitude smaller than the individual radiative and turbulent flux components (e.g., van As 
et al., 2005; Fisher et al. 2015), though it can become somewhat important on sub-daily timescales (i.e., warming of the snowpack in the morning and cooling at night, after potential refreezing).

If the ME remains positive across at least two diurnal cycles, then this condition combined with skin or $2 \mathrm{~m}$ air temperatures at or just below freezing is often associated with a surface melt that is detectable in satellite passive microwave (PMW) data (Nicolas et al., 2017). This does not mean that surface melt is occurring throughout those diurnal cycles. Melt occurs only when $T_{\mathrm{s}}$ is between -2 and $0{ }^{\circ} \mathrm{C}$, depending on surface microphysics. At colder $T_{\mathrm{s}}$, the positive ME goes into warming the snowpack but does not cause detectable melt. The PMW data are instantaneous observations made twice daily (morning and evening overpasses). If the PMW-measured brightness temperature ( $T_{\mathrm{b}}$, Sect. 2.1 below) is consistent with a significant increase in surface emissivity as compared with the previous observation, this signifies a moistening of surface firn layer and/or accumulation of meltwater in response to a positive $\mathrm{ME}$ at $T_{\mathrm{s}} \geq-2{ }^{\circ} \mathrm{C}$. Identification of a time interval in the ME time series that remains positive across two or more diurnal cycles should therefore be regarded as a strong indicator of satellite-detectable melt at some point during the interval.

The largest individual terms in Eq. (1) are the upwelling and downwelling radiative fluxes, and they are strongly modulated by cloud cover, which is extensive over West Antarctica (Scott et al., 2017). Therefore the net (downwelling minus upwelling) radiative fluxes are just as capable of driving ME $>0$ for extended time periods as a strong impulse of positive SH flux. The result is that three distinct mechanisms for inducing surface melt can be at play over West Antarctic ice sheets, either individually or in conjunction reinforcing each other.

One mechanism is thermal blanketing. If an air mass contains overcast cloud cover within a few hundred meters of the surface having liquid water path (LWP) $>50 \mathrm{~g} \mathrm{~m}^{-2}$, this cloud cover will radiate in the LW as a blackbody at very close to surface temperature, while also attenuating the net SW flux. The result is a surface net LW flux close to zero, and sometimes even positive, along with a constantly positive net SW flux that has a diurnal cycle of relatively small amplitude. If the net turbulent flux is also positive such that the ME remains positive over two more diurnal cycles, this will usually induce surface melt, if the starting skin temperature is warm enough (e.g., Trusel et al., 2013). This situation prevailed during the large-scale January 2016 melt event over West Antarctica (Nicolas et al., 2017). Wille et al. (2019) have correlated most Antarctic surface melt events with the presence of atmospheric rivers (ARs). If ARs impinging on the Antarctic continent tend to bring mainly large cloud LWP, then thermal blanketing would be a widespread source of stress on the ice shelves.

A second mechanism involves an all-wave (SW plus LW) radiative enhancement by optically thin clouds. Ben- nartz et al. (2013) discovered this cloud radiative effect and showed that it is extensive over the Greenland Ice Sheet (GIS) during warm summers that drive surface melt. When overcast or broken cloud cover has LWP between $10-40 \mathrm{~g} \mathrm{~m}^{-2}$, generally very common in the Antarctic atmosphere (e.g., Bromwich et al., 2012; Scott and Lubin 2014, 2016), this cloud cover will radiate substantially toward the surface in the LW while still allowing large SW fluxes to reach the surface. In combination with a mostly positive net turbulent flux, these clouds can often prolong a positive ME over multiple diurnal cycles, causing surface melt. Van Tricht et al. (2016) found an additional role for optically thin low cloud cover in slowing down the refreezing of meltwater, and this effect may also appear in one of our case studies.

A third mechanism very common throughout Antarctica is a föhn wind (Elvidge and Renfrew, 2016). The föhn effect occurs when an air mass crosses high terrain such as a mountain range. As the air mass is forced upslope it expands and cools, and the moisture condenses and may form clouds or precipitation, releasing latent heat. Adiabatic descent on the lee side of the high terrain warms the air even more substantially than the latent heat release and, combined with turbulent mixing upon reaching the lower terrain, brings a large positive turbulent flux input to the surface, potentially great enough to initiate surface melt. Föhn winds are especially prevalent on the lee side of the Antarctic Peninsula, causing stress to the Larsen C Ice Shelf (e.g., Elvidge et al., 2015; King et al., 2017; Datta et al., 2019). However, due to widely varying high terrain over Antarctica, in particular the Transantarctic Mountains, föhn winds can occur and impact an ice shelf depending on whether the prevailing synoptic conditions yield airflow perpendicular to mountainous terrain (e.g., Zou et al., 2018).

\subsection{Melt detection}

We identify the Antarctic surface melt events with a standard PMW technique using the Defense Meteorological Satellite Program Special Sensor Microwave Imager/Sounder (SSMIS), but with a new NASA-supported Making Earth System Data Records for Use in Research Environments (MEaSUREs) data product archived at the National Snow and Ice Data Center (NSIDC). We use the Equal-Area Scalable Earth Grid version 2 (EASE-Grid 2.0) Level-2 PMW brightness temperature $\left(T_{\mathrm{b}}\right)$ at $19.35 \mathrm{GHz}$ with horizontal polarization ( $19 \mathrm{GHz}-\mathrm{H}$; K-band) from the evening overpass at $25 \mathrm{~km}$ grid spacing (Brodzik et al., 2016, updated 2020). We base our melt detection technique on an algorithm originally proposed by Zwally and Feigles (1994) and subsequently refined and validated by Torinesi et al. (2003) and Tedesco (2009). For a given grid cell, surface melt is detected when the PMW $T_{\mathrm{b}}$ measurement exceeds the prior cold season average by $30 \mathrm{~K}$. The cold season average is constructed by averaging daily $T_{\mathrm{b}}$ measurements from 1 April of the prior year through 31 March of the given year. This average is then repeated 
twice, each time after removing daily values $>30 \mathrm{~K}$ above the previous average.

This technique is generally used to detect and map surface melt over large areas and on seasonal timescales. Here we examine monthly $T_{\mathrm{b}}$ time series in the three regions depicted in Fig. 1. The Pine Island and Thwaites Glacier region presents the greatest concern for West Antarctic Ice Sheet (WAIS) loss (e.g., Alley et al., 2015). Siple Dome is a site at an intermediate elevation on the WAIS (607 ma.s.1.) that has a multi-decadal automatic weather station (AWS; Lazzara et al., 2012) record and a US Antarctic Program (USAP) summer field camp that has been used for some field work on the physics of snowmelt (Das and Alley 2005, 2008). Siple Dome is considered here because it is accessible by the US Antarctic Program for future field work. In addition to the AWS, the University of Wisconsin Antarctic Meteorological Research Center archives manual surface weather observations from numerous field camps and expeditions, and some of these are available for our case studies, over Pine Island Glacier and Siple Dome.

We choose a third location on the Ross Ice Shelf (RIS) near the Transantarctic Mountains that contains two AWSs, Tom $\left(84.430^{\circ} \mathrm{S}, 171.455^{\circ} \mathrm{W}\right)$ and Sabrina $84.248^{\circ} \mathrm{S}$, $170.044^{\circ} \mathrm{W}$ ), whose data have suggested the presence of strong föhn winds. In the AWS measurements, a föhn condition can be inferred from an increase in wind speed along with a south to southeasterly wind direction from the Transantarctic Mountains. Each of the regions depicted in Fig. 1 contains between 800-1300 $25 \mathrm{~km}$ EASE-Grid cells. This gives us an opportunity to examine local-scale spatial variability resulting perhaps from varying topography or differential melting and refreezing frequency across the local domain, in addition to time variation. In the monthly $T_{\mathrm{b}}$ time series, we identify melt events of short duration $(<5 \mathrm{~d})$ by comparing the daily mean, median, and range with the prior cold season average and the $30 \mathrm{~K}$ melt detection threshold. Short duration melt events provide relatively straightforward case studies in which we can readily identify the changing meteorological conditions and shifts in individual ME components that lead to melt onset and subsequent recovery. Such case studies allow us to observe the basic physics and develop an understanding of what is driving these surface melt events at a local spatial scale.

\subsubsection{Surface energy budget analysis}

For our SEB analysis, we use the fifth-generation ECMWF meteorological reanalysis data (ERA5; Hersbach et al., 2020). Previous studies have shown better agreement between ECMWF data and Antarctic in situ data than other reanalysis models (e.g., Lenaerts et al., 2017). The ERA5 model physics includes prognostic determination of cloud water and ice, cloud fraction, rain and snow (Hersbach et al., 2020), more modern atmospheric radiative transfer schemes than its predecessor ERA-Interim (Dee et al., 2011), and a so- phisticated snow component in the land surface model (Dutra et al. 2010). We compute ME using the surface radiative and turbulent fluxes on a $0.5^{\circ} \times 0.5^{\circ}$ latitude-longitude grid with hourly time resolution. Other ERA5 fields we analyze include the near-surface $(2 \mathrm{~m})$ air temperature, skin temperature, and $850 \mathrm{hPa}$ wind components.

Because of known errors in polar cloud microphysics simulated by ERA5 and other reanalysis and regional models (e.g., Silber et al., 2019), we found it necessary to supplement the ERA5 ME calculations with satellite-retrieved cloud properties. We therefore use satellite data products from the NASA Clouds and the Earth's Radiant Energy System (CERES) program - specifically, the synoptic 1-degree (SYN1deg) data product. Here CERES top-of-atmosphere (TOA) fluxes, surface fluxes, cloud masking, and cloud properties are interpolated to hourly time resolution using geostationary satellite data and gridded to $1^{\circ}$ in both latitude and longitude. The SYN1deg product contains NASA A-Train retrievals of cloud LWP and ice water path (IWP) based primarily on the Moderate Resolution Imaging Spectroradiometer (MODIS) data from the Aqua spacecraft (Rutan et al., 2015). Radiometric calibration uncertainty with the MODIS sensor itself is generally taken to be $5 \%$ in all bands for the purpose of evaluating retrieval uncertainties (Platnick et al., 2017). In the MODIS radiative-transfer-based retrieval algorithms that use an independent homogeneous pixel approximation, uncertainty in cloud optical depth is of order $10 \%$ in the range 3-20 (Platnick et al., 2004, 2017) and increases for both smaller and larger cloud optical depths. Over polar regions, Khanal and Wang (2018) have identified additional uncertainties and biases resulting from mixed-phase cloud effects, large solar zenith angles, and cloud spatial inhomogeneity. For the purpose of this study, MODIS-based cloud property retrievals have shown consistency with groundbased remote sensing data from West Antarctica (Wilson et al., 2018), sufficient to discriminate between optically thin and optically thick clouds associated with the distinct mechanisms that induce surface melt.

We analyze our case studies by calculating the ME with ERA5 radiative and turbulent fluxes and then examine the CERES SYN1deg cloud LWP and IWP as a separate check on the realism of cloud properties simulated by ERA5. Justification for this approach is given in Appendix A.

\section{Results and discussion}

We organize this work into four case studies, the first three of which involve synoptic conditions that drive surface melt events lasting several days at one location. The final case involves synoptic conditions that drive surface melt over the entire Amundsen Sea Embayment (ASE), with contrasting mechanisms at each of the locations considered herein. 


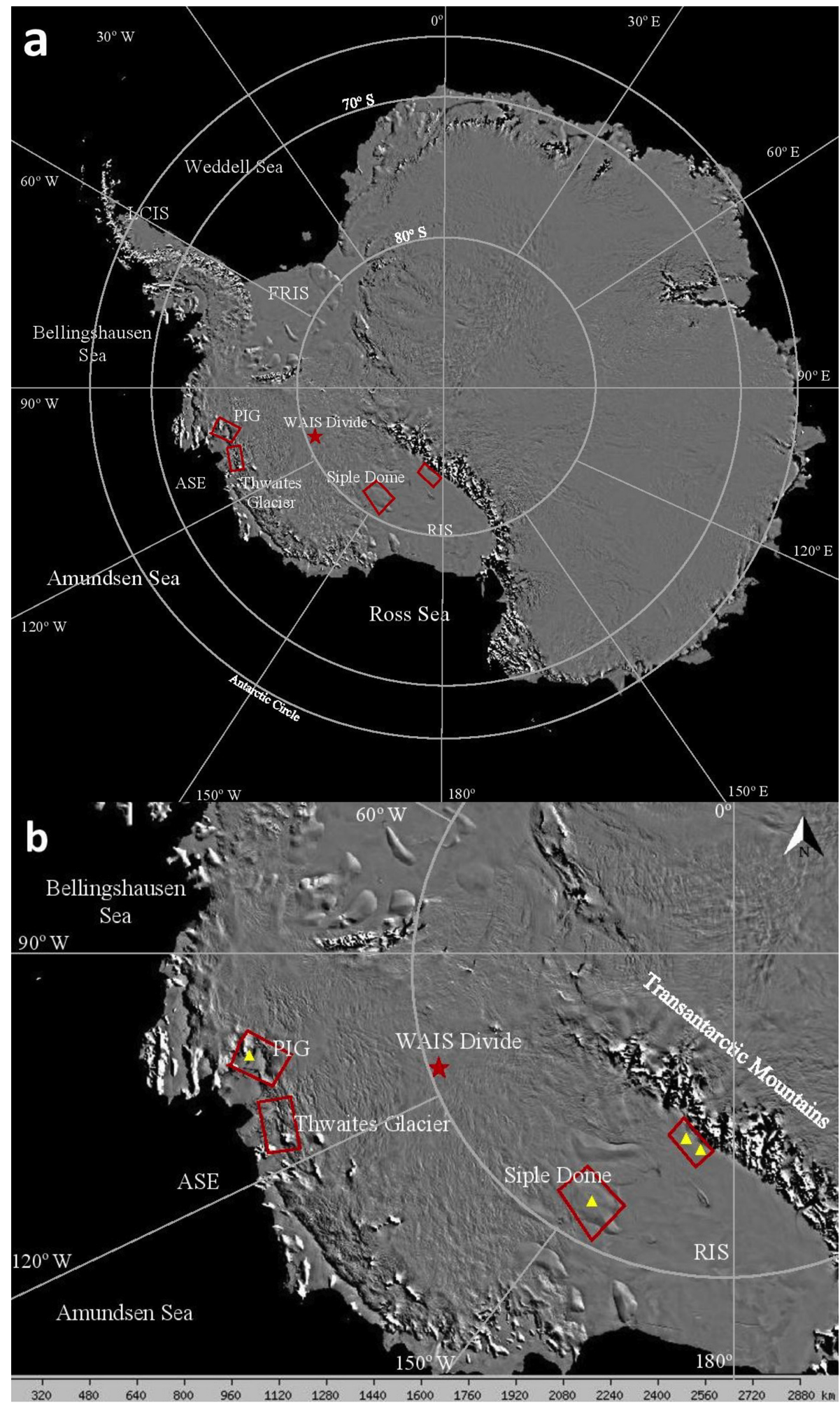

Figure 1. Maps of (a) Antarctica and (b) West Antarctica showing the case study locations. The red boxes depict the regions from which the satellite and reanalysis data are extracted for analysis. The AWARE data were collected at the WAIS Divide ice camp, shown by the red star. The locations of automatic weather stations are shown as yellow triangles. Abbreviations are Ross Ice Shelf (RIS), Amundsen Sea Embayment (ASE), Pine Island Glacier (PIG), Filchner-Ronne Ice Shelf (FRIS), and Larsen C Ice Shelf (LCIS). Figure constructed from the Mosaic of Antarctica (Scambos et al. 2007; Haran et al., 2014). 


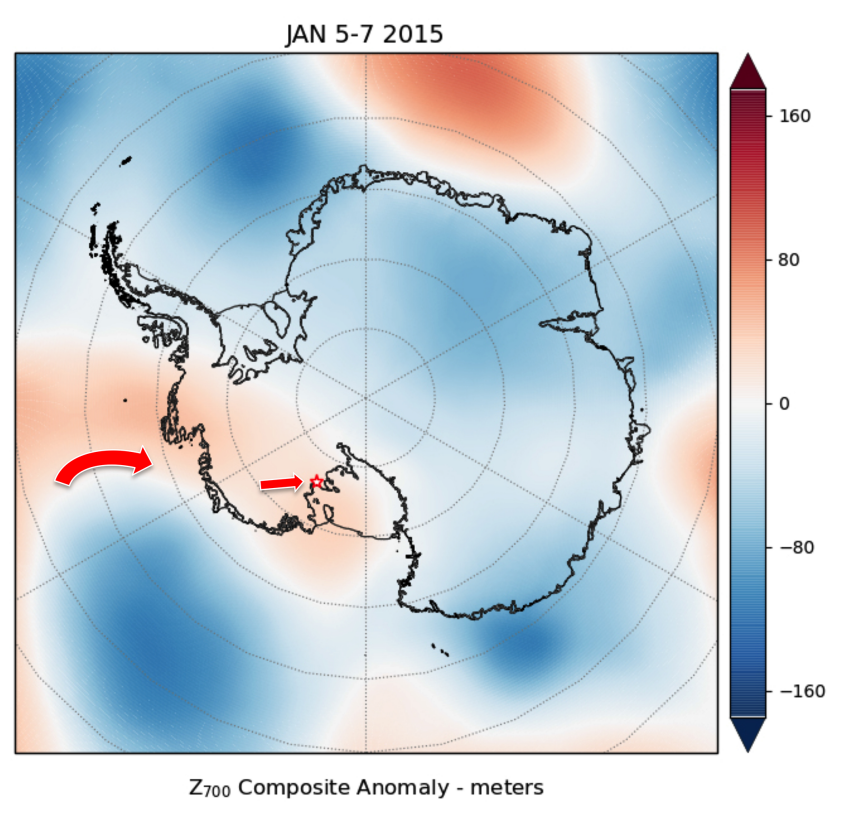

Figure 2. Composite anomaly of ERA5 $700 \mathrm{hPa}$ geopotential height for 5-7 January 2015. The red star depicts the location of Siple Dome. The red arrows depict the direction of $700 \mathrm{hPa}$ winds relevant to the case study.

\subsection{Siple Dome January 2015}

Our first case study reveals evidence of an all-wave radiative enhancement by optically thin clouds, which led to satellitedetected surface melt on Siple Dome between 5-7 January 2015. As seen in Fig. 2, during these days a low-pressure system over the Ross-Amundsen Sea experienced blocking by a weak ridge of high pressure. This synoptic setup drove a warm, moist marine air intrusion over Marie Byrd Land, which subsequently descended over Siple Coast, causing adiabatic warming and drying of the air mass. This descent may have reduced the optical thickness of any previously thick clouds into the Bennartz et al. (2013) thin cloud range $\left(\mathrm{LWP}=10-40 \mathrm{~g} \mathrm{~m}^{-2}\right)$.

Figure 3a shows the daily $T_{\mathrm{b}}$ statistics throughout the Siple Dome region depicted in Fig. 1. The surface melt detected by the satellite, using the $30 \mathrm{~K}$ threshold, begins in some of the region on 5 January and extends through most of the region over the next $2 \mathrm{~d}$. This is seen in the relative number of $T_{\mathrm{b}}$ data points above and below the $30 \mathrm{~K}$ threshold as depicted by the daily box plots. Figure $3 \mathrm{~b}$ shows estimates of the surface emissivity sampled from five grid cells with $T_{\mathrm{b}}$ values ranging from the 5th to 99th percentiles on 6 January. These grid cells were chosen from within the Siple Dome region with the criteria that they have a fully overlapping ERA5 grid cell and span a range of the 5th to 99th percentile referenced to the max $T_{\mathrm{b}}$ observed in the region. Here surface emissivity is approximated as the ratio of the satellite-measured $T_{\mathrm{b}}$ to the ERA5 skin temperature. Before this short melt event, and also beginning $4 \mathrm{~d}$ after it ends (after the 12th), the surface emissivity appears to be spatially uniform. During the melt period the surface shows large variability in emissivity throughout the region, possibly reflecting differential surface properties resulting from non-uniform snow accumulation or refreezing from prior melt periods. Examples of spatial variability in the satellite-measured $T_{\mathrm{b}}$, on the day when the surface melt is most pronounced, are shown in Appendix B.

Figure 4 presents time series of the individual ME components. The shaded period of interest contains the melt onset, peak, and decrease to when most pixels show no satellitedetected melt. Cloud cover reduces the net SW flux to a monthly minimum on 6 January, while at the same time the net $\mathrm{LW}$ flux rises from $<-50$ to $\sim-25 \mathrm{Wm}^{-2}$ (Fig. 4a). The total net radiation is at a monthly maximum on 6 January (Fig. 4b). SH flux is small but mostly positive between 59 January (Fig. 4c), resulting from warmer air just above the surface, but this is largely canceled by mostly negative LH flux so that the net turbulent flux (Fig. 4d) does not remain positive over more than one entire diurnal cycle between 59 January. The ME remains positive over two full diurnal cycles on 6 and 7 January (Fig. 4e) but at no other time in January. This corresponds with a monthly maximum in $2 \mathrm{~m}$ air temperature and skin temperature (Fig. 4f).

Cloud LWP and IWP (Fig. 5) show discrepancies between ERA5 and CERES SYN1deg but overall suggest the presence of optically thin cloud cover. ERA5 predicts very low LWP but an impulse of high IWP on 6 January. This may be unrealistic, as Silber et al. (2019) show that ERA5 often produces too much cloud ice water and too little cloud liquid water over West Antarctica. In contrast, CERES data indicate low IWP but an impulse of elevated LWP that briefly reaches a maximum of $49 \mathrm{~g} \mathrm{~m}^{-2}$ on 6 January. Throughout 5-9 January, the CERES average LWP is $21.2 \pm 13.7 \mathrm{~g} \mathrm{~m}^{-2}$. We note that the ERA5 radiative transfer algorithm uses the high IWP values when computing the SW and LW fluxes in Fig. 4a and $b$. Examining the vertical profiles in cloud water content over 5-9 January, we find that maximum liquid water content occurs mainly in the pressure range $850-950 \mathrm{hPa}$, while maximum ice water content occurs in the more vertically extensive pressure range $700-850 \mathrm{hPa}$ (figure not shown). Although the ERA5 IWP values exceed $80 \mathrm{~g} \mathrm{~m}^{-2}$ on 6 January, they are still likely to manifest as an optically thin cloud in the radiative transfer calculation if the effective cloud particle size is in the range $40-50 \mu \mathrm{m}$ observed for Antarctic clouds (e.g., Scott and Lubin, 2016). In this case, the cloud optical depth would most likely be less than 5, as opposed to a liquid water cloud that, with effective droplet radius of order 7-10 $\mu \mathrm{m}$, would have an optical depth of order 1015 and would therefore radiate in the LW as a blackbody at a temperature characteristic of the pressure range 850$950 \mathrm{hPa}$. The higher and more vertically extensive range of the ERA5 cloud ice water content on 6 January also signifies colder radiating temperature and therefore smaller LW flux emitted to the surface. This case study underscores the need 

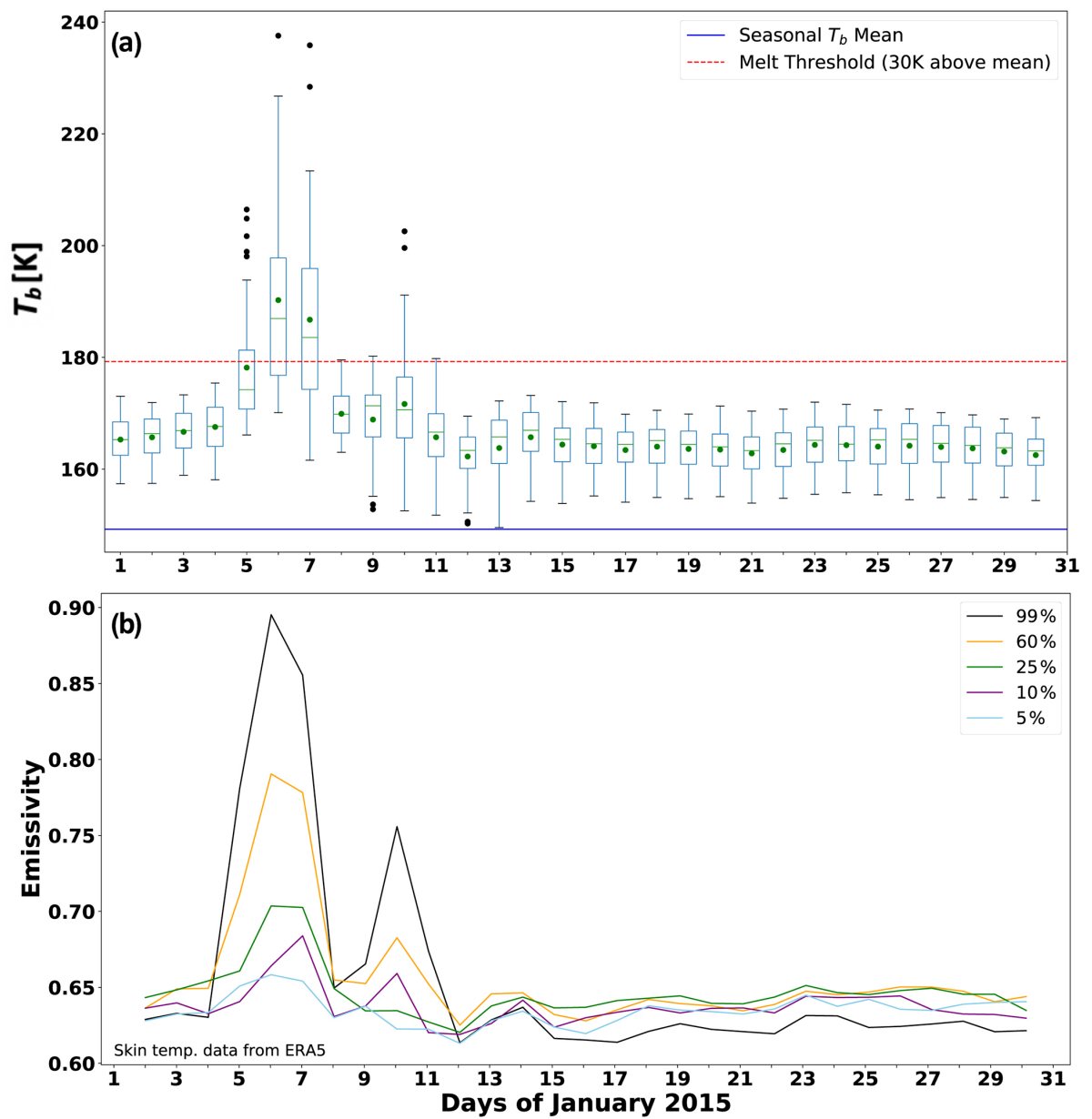

Figure 3. (a) Time series of daily evening overpass SSMIS brightness temperatures $T_{\mathrm{b}}$ over the Siple Dome region during January 2015 as daily statistics, with the box denoting the first to third interquartile range $\left(Q_{1}\right.$ to $\left.Q_{3}\right)$, the horizontal line in the box denoting the median, the green dot denoting the mean, the whiskers denoting the distance $1.5\left(Q_{3}-Q_{1}\right)$, and individual black points beyond them denoting outliers beyond the range $1.5\left(Q_{3}-Q_{1}\right)$. The blue horizontal line is the prior cold season mean, and the red horizontal line is the standard melt detection threshold lying $30 \mathrm{~K}$ above the prior cold season mean (Tedesco 2009). (b) Five estimates of surface emissivity sampled throughout the region with percentiles referenced to the maximum $T_{\mathrm{b}}$ value in the region on 6 January.

for improvement in mixed-phase cloud microphysics used in reanalysis models. Gilbert et al. (2020) have demonstrated how surface SW and LW fluxes governing surface melt on the Larsen C Ice Shelf are sensitive to cloud vertical profile as well as thermodynamic phase, and the same considerations apply to West Antarctica. We also note that CERES data show a second impulse in cloud LWP on 9 January. Being absent in the ERA5 cloud simulation, its effect does not appear in the radiative fluxes in Fig. 6a and b. However, it may help to explain the satellite $T_{\mathrm{b}}$ signals of partial surface melt in the region that persist until 11 January (Fig. 3). This may be an example of the refreezing inhibition proposed by Van Tricht et al. (2016).

Field camp observations between 5-9 January indicate mostly broken and overcast cloud cover with cloud bases between $900-1800 \mathrm{~m}$ and unrestricted visibility, occasionally dropping to $\sim 250 \mathrm{~m}$ in reduced visibility with freezing fog or mist and light fog during 8 and 9 January. On 5 and 6 January the observer remarks "Sun dimly visible" through the overcast. These observations are qualitatively consistent with optically thin cloud cover.

\subsection{Pine Island and Thwaites glaciers January 2012}

We next investigate a melt event that is clearly driven by clouds, during synoptic conditions that normally do not favor surface melt. Early January 2012 experienced strong positive Southern Annular Mode (SAM) conditions, as evidenced by the anomalously low geopotential heights over Antarctica in Fig. 6. Such conditions, accompanied by strong circumpolar westerly flow, are associated with reductions in meridional heat exchange with lower latitudes. Therefore, this scenario is typically not conducive to melting on the ASE region (Scott et al. 2019). However, during the brief period of 

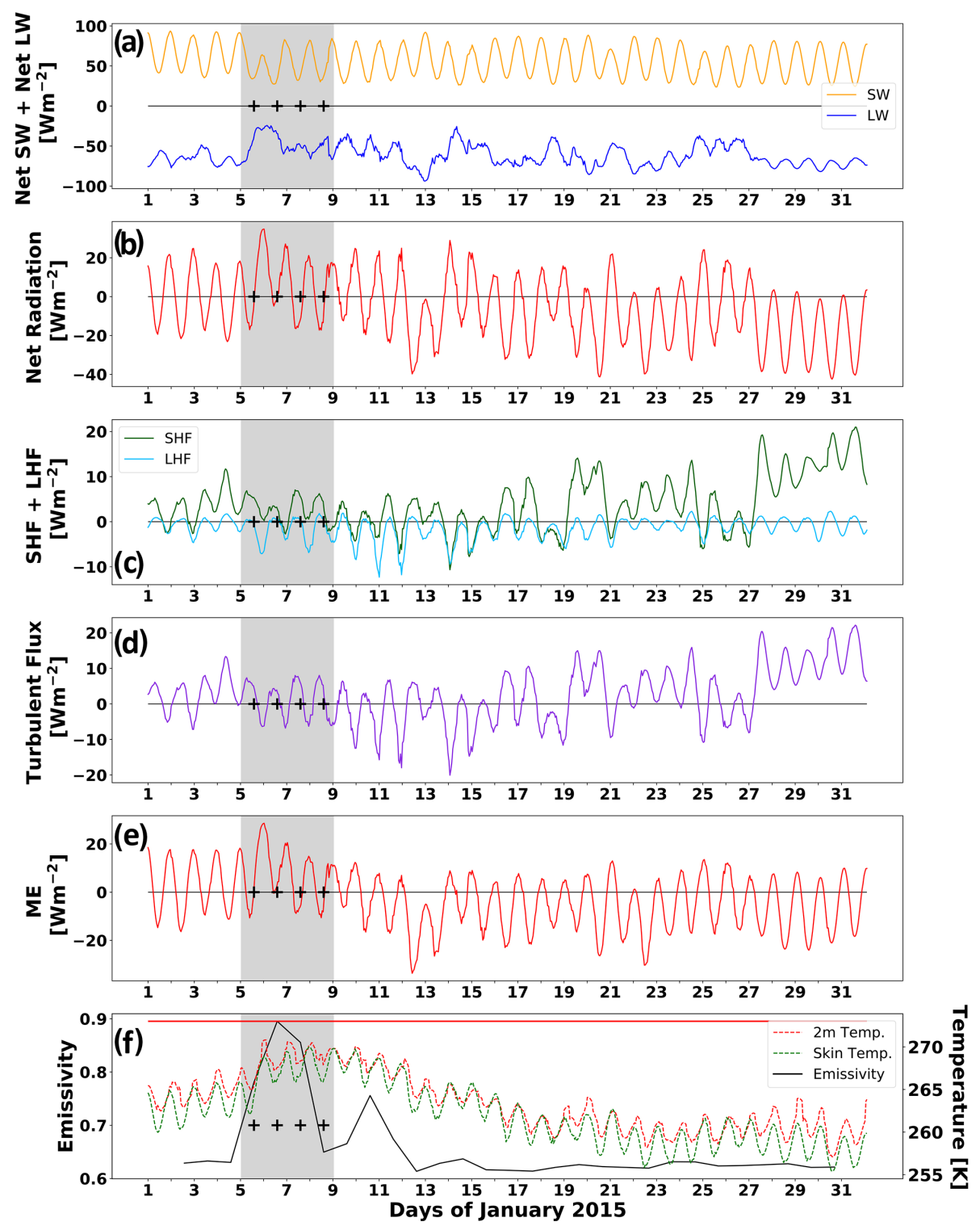

Figure 4. Time series of the hourly ME components over the Siple Dome region throughout January 2015 from ERA5: (a) individual net SW and LW fluxes; (b) total net radiative flux (SW + LW); (c) individual SH and LW fluxes; (d) net turbulent flux (SH + LH); (e) total ME; (f) skin temperature (green), $2 \mathrm{~m}$ air temperature (red), and sampled 99th percentile emissivity from Fig. 3b (black). The horizontal red line in panel (f) is at $273.15 \mathrm{~K}$. The shaded region denotes the melt period of interest. Black crosses denote the satellite evening overpass times.

interest, a high-pressure ridge developed over the northern Amundsen Sea, off the tip of South America (not shown). This briefly diverted the large-scale flow toward the ASE region and provided an impulse of heat and moisture to the area.

Our period of interest shows a modest melt signal (Fig. 7a), with the mean satellite PMW $T_{\mathrm{b}}$ reaching the standard $30 \mathrm{~K}$ detection threshold only on 6 January. However, we note that throughout January 2012 the upper bound of the $T_{\mathrm{b}}$ sample is near or slightly above the $30 \mathrm{~K}$ detection threshold. In Fig. $7 b$ we see that all the sampled surface emissivity estimates are larger than 0.8 , in contrast to the lower values observed over Siple Dome outside of melt periods.

During our period of interest 4-8 January, the radiative fluxes show a strong modulation by cloud cover (Fig. 8a), with net SW flux attenuated by nearly a factor of 2 relative to most of the rest of the month, and with net $\mathrm{LW}$ driven to nearly zero. The result is that the net total radiative flux remains positive across three diurnal cycles. The $\mathrm{SH}$ and $\mathrm{LH}$ fluxes (Fig. 8c) are much smaller in amplitude, and the net turbulent flux drops below zero every day (Fig. 8d). It is primarily the radiative flux terms that keep the ME positive across nearly four diurnal cycles (Fig. 8e). The corre- 

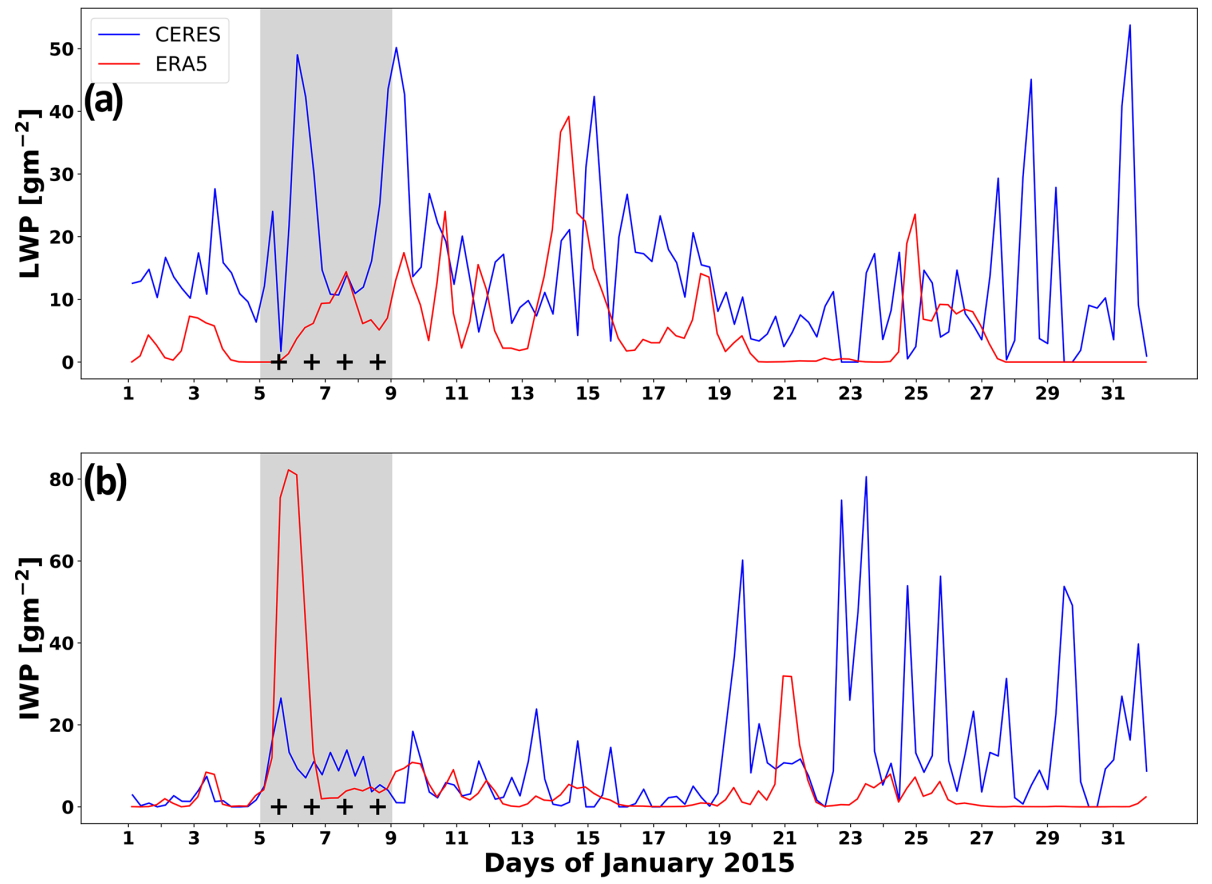

Figure 5. Time series of hourly cloud LWP (a) and IWP (b) from the CERES SYN1deg data product (red) and ERA5 (blue), over the Siple Dome region throughout January 2015. Black crosses denote the satellite evening overpass times.

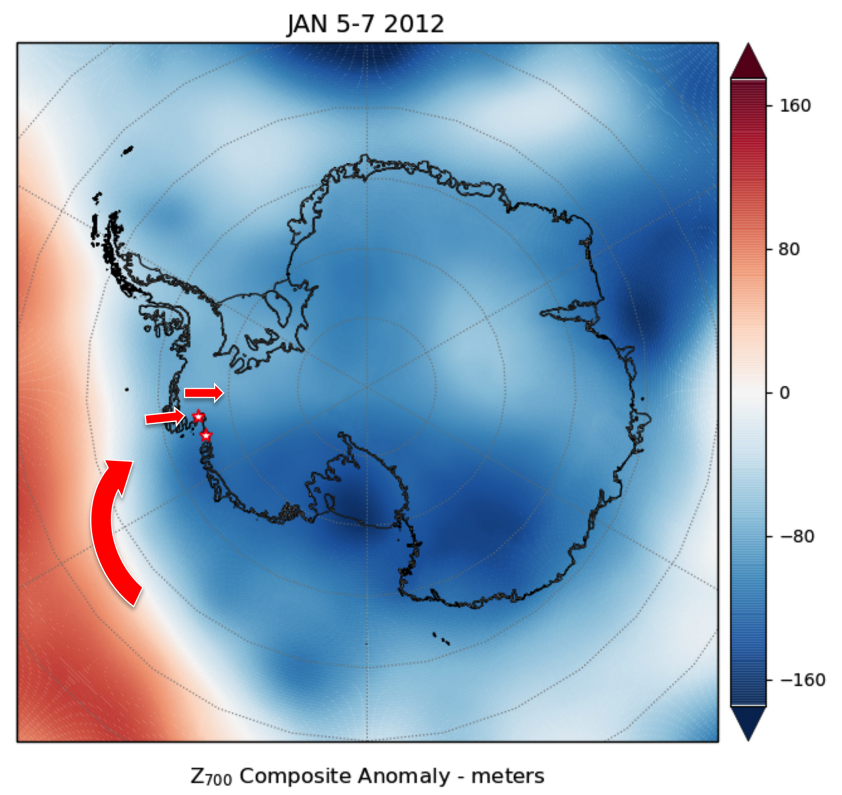

Figure 6. Composite anomaly of ERA5 $700 \mathrm{hPa}$ geopotential height for 5-7 January 2012. The red stars depict the locations of Pine Island and Thwaites glaciers. The red arrows depict the direction of $700 \mathrm{hPa}$ winds relevant to the case study.

sponding $2 \mathrm{~m}$ air and skin temperatures rise steadily during this interval to a monthly maximum on 7 January (Fig. 8f), which is the second strongest day in the satellite melt de- tection signal (Fig. 14a). We note that two other short periods, 16 and 17 January and 20 and 21 January, show ME $>0$ across two diurnal cycles. However, the $2 \mathrm{~m}$ air and skin temperatures are well below freezing during these periods, and satellite melt signatures are barely detectable (Fig. 7). During 4-8 January the $2 \mathrm{~m}$ air and skin temperatures approach freezing, which is generally necessary for melt onset even when the primary energy input is from a cloud radiative impulse.

The cloud LWP estimates (Fig. 9a) show consistency between ERA5 and CERES during 4-8 January, although ERA5 appears to underpredict LWP for most of the rest of the month. ERA5 again appears to overpredict IWP during the melt period of interest, by more than a factor of 2 compared with CERES. During 4-8 January the CERES LWP is mostly within the thin cloud range $\left(10-40 \mathrm{~g} \mathrm{~m}^{-2}\right)$ associated with the Bennartz et al. (2013) all-wave radiative effect. CERES IWP is almost as large as the LWP, which again may reflect errors in MODIS-based phase discrimination. Considering the CERES combined LWP and IWP, it remains unclear if the cloud radiative impulse (Fig. 8a and b) is due to the Bennartz et al. (2013) all-wave effect or to thermal blanketing by optically thicker cloud cover. And the ERA5 radiative transfer algorithm produces the fluxes in Fig. 8a using the large cloud IWP values that are almost certainly in error. This case study clearly shows the role of clouds in altering the ME to enhance surface melt but also underscores the need to improve both satellite retrieval and reanalysis cloud microphysics to obtain a complete understanding. 

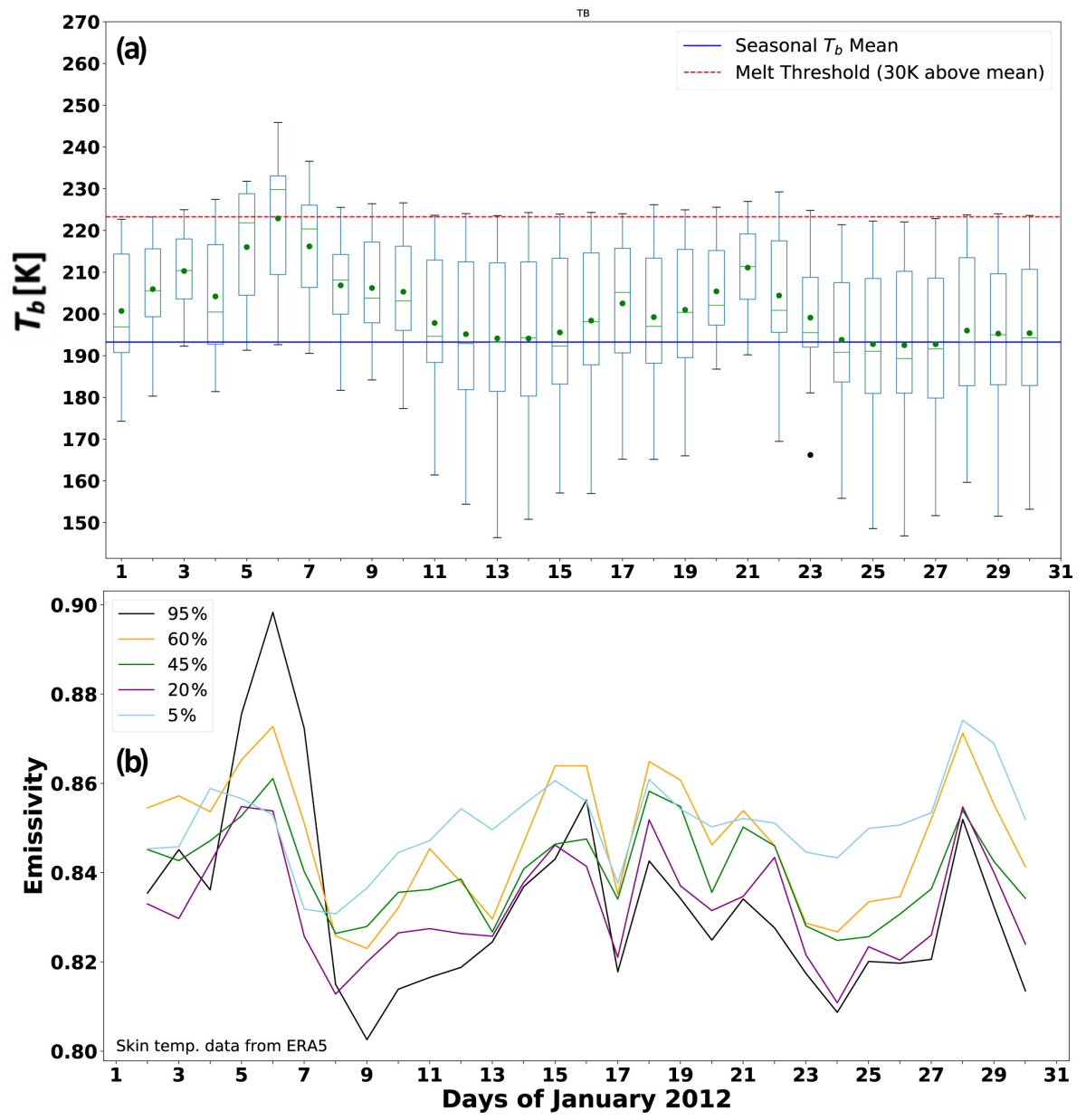

Figure 7. As in Fig. 3 but over the Pine Island and Thwaites Glacier region throughout January 2012. The five estimates of surface emissivity in panel (b) sampled from the region are referenced to the maximum $T_{\mathrm{b}}$ value in the region on 6 January.

The field camp on Pine Island Glacier recorded broken to overcast cloud cover with bases $300-600 \mathrm{~m}$ on 4 January, with ceilings dropping to $150 \mathrm{~m}$ on 5 January. On 6 and 7 January at least two cloud layers were observed, with variable ceilings mostly below $2000 \mathrm{~m}$. Throughout 8 January sky coverage steadily reduces from broken to scattered/few clouds. Light snowfall is the most consistent present-weather condition between 4-8 January, but there are also episodes of mist, freezing fog, drifting snow, and blowing snow. Qualitatively these observations might suggest optically thicker cloud cover.

\subsection{Pine Island and Thwaites glaciers February 2013}

We now examine a late summer melt event driven by thermal blanketing on Pine Island and Thwaites glaciers in February, when climatological surface and lower tropospheric temperatures are typically several degrees cooler than in January. During late February 2013, an amplified ridge of high pressure developed and remained stationary over the AmundsenBellingshausen seas (Fig. 10). At the same time, a low- pressure system formed and deepened over the Ross Sea. This resulted in strong and sustained meridional flow of heat and moisture into West Antarctica, which lasted for $5 \mathrm{~d}$. Such synoptic conditions are highly conducive to surface melting along the West Antarctic coastline and were likely critical for causing the observed late-summer melt. This synoptic pattern is a signature of the Amundsen Sea Low (Turner et al., 2013; Clem et al. 2017) and is representative of frequent surface melting in the area (Scott et al., 2019).

In Fig. 11a, satellite PMW data show a 3 d, partial-surfacemelt signature in the Thwaites and Pine Island Glacier region from 20-22 February 2013. Surface emissivity (Fig. 11b) has relatively large spatial variability throughout this local region. For our melt period of interest between 19-21 February, the radiative fluxes (Fig. 12a) show a clear signature of thermal blanketing by optically thick cloud cover. The net SW flux is attenuated by a factor of 3 compared with the earlier weeks in February, such that its diurnal amplitude is only $\sim 20 \mathrm{~W} \mathrm{~m}^{-2}$. The LW flux is positive, signifying optically thick clouds that are warmer than the surface. The net 

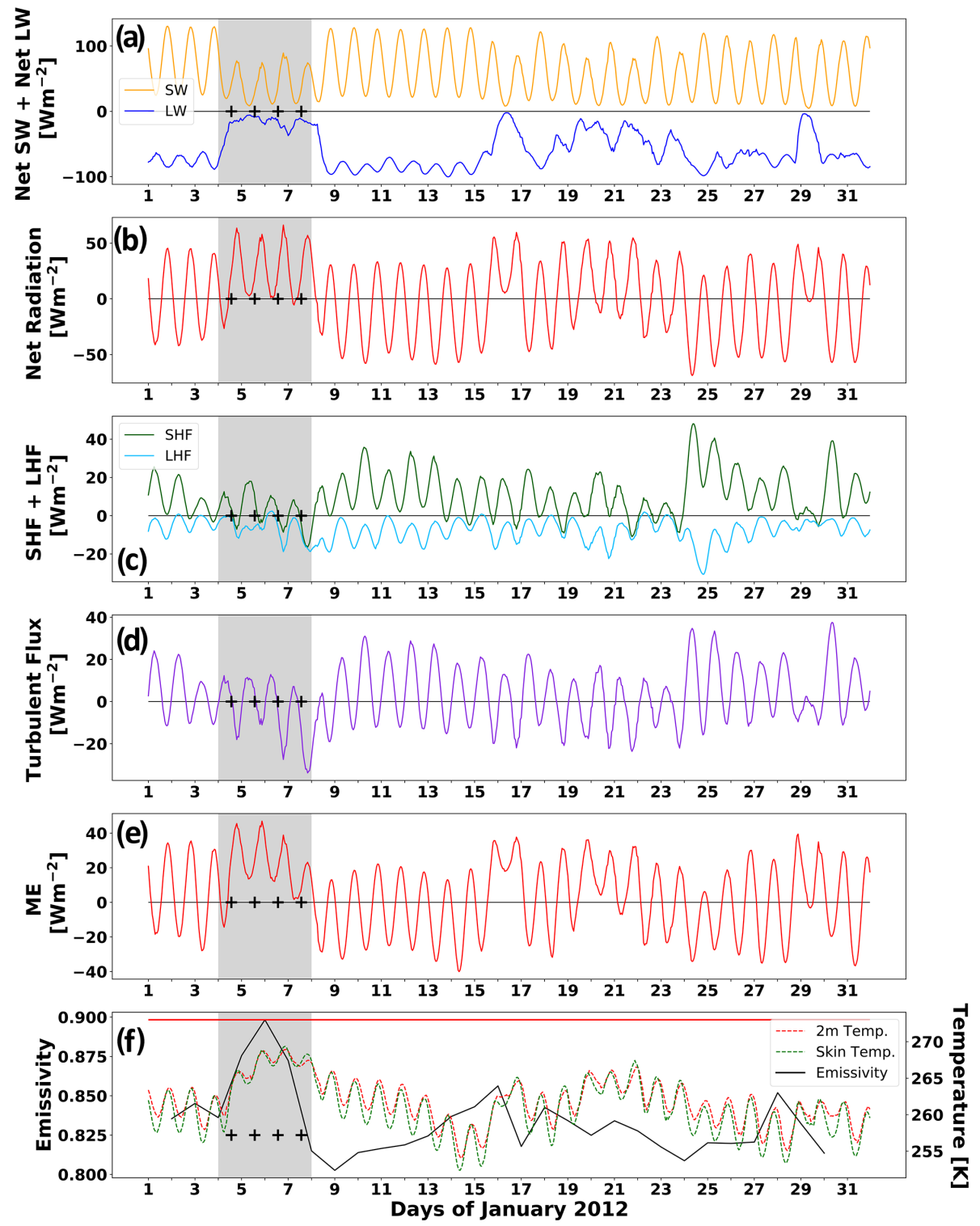

Figure 8. As in Fig. 4 but over the Pine Island and Thwaites Glacier region throughout January 2012.

radiative flux (Fig. 12b) is positive over the diurnal cycles on 20 and 21 February. We also find positive SH flux (Fig. 12c) that yields positive net turbulent flux (Fig. 12d) across the entire melt period of interest. This positive turbulent flux is comparable in magnitude if not greater than the net radiative flux between 19-21 February. Then between 21-23 February, as the cloud radiative effect diminishes such that the net radiation drops below zero each day, the $\mathrm{SH}$ flux doubles in magnitude to sustain the positive ME until 23 February (Fig. 12e). The result is a steady rise in $2 \mathrm{~m}$ air and skin temperatures from 20 February, when the satellite melt signature is first detected, to nearly the freezing point by 21 February and staying this warm for another $4 \mathrm{~d}$. Even though these temperatures remain close to the freezing point for several days, the satellite melt signature decreases as the ME decreases and resumes a diurnal cycle that drops below zero.

The cloud properties during this melt period (Fig. 13) are mainly consistent with large optical thickness. The CERES average LWP and IWP are $34.9 \pm 25.8$ and $47.8 \pm 27.4 \mathrm{~g} \mathrm{~m}^{-2}$, respectively. While this larger IWP may reflect errors in phase discrimination, the suggested total cloud water content is higher than that associated with the Bennartz et al. (2013) all-wave effect and instead indicates primarily a longwave surface warming where a low cloud radiates as a blackbody, with a muted SW diurnal signal. ERA5 LWP and IWP are significantly larger than the CERES retrievals and may be overestimated due to microphysical errors, but their timing is consistent with the CERES detection of optically thick clouds. In this case study, we therefore see 

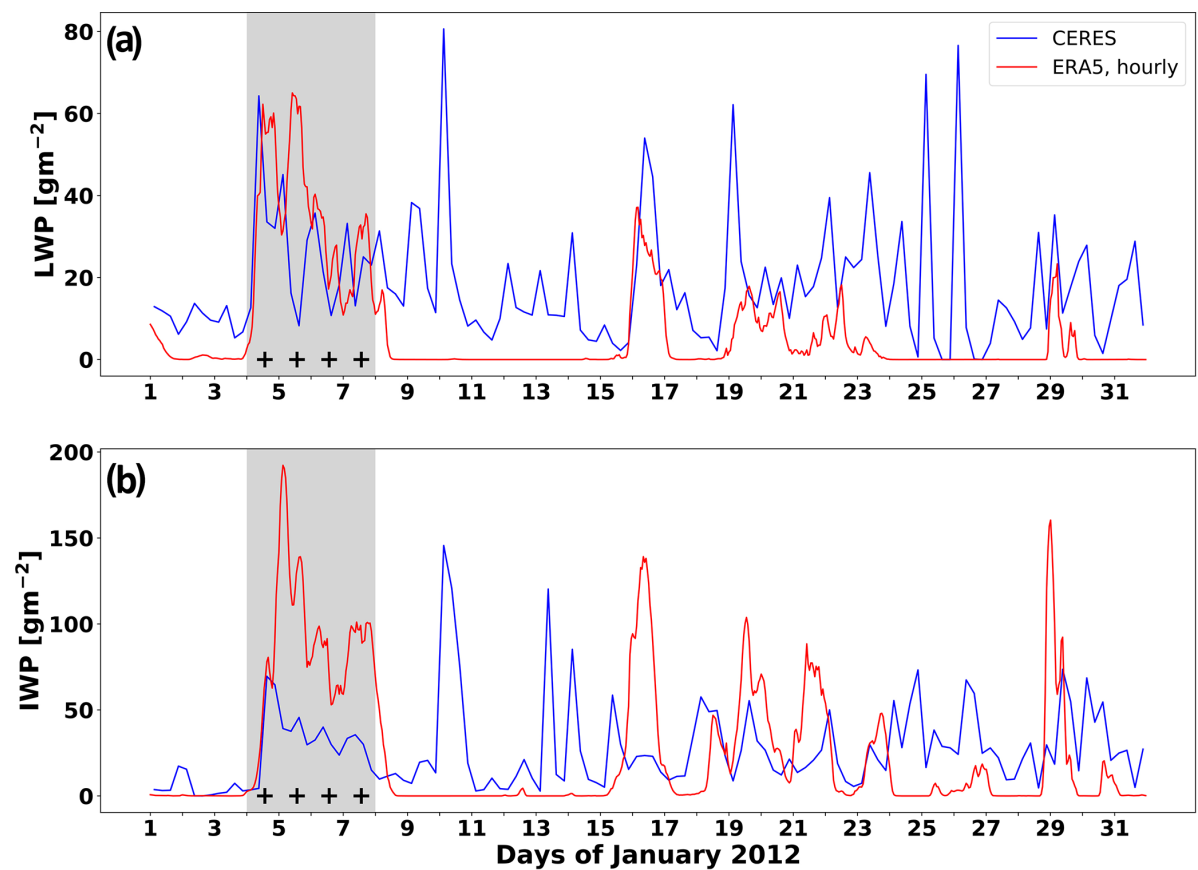

Figure 9. As in Fig. 5 but over the Pine Island and Thwaites Glacier region throughout January 2012.

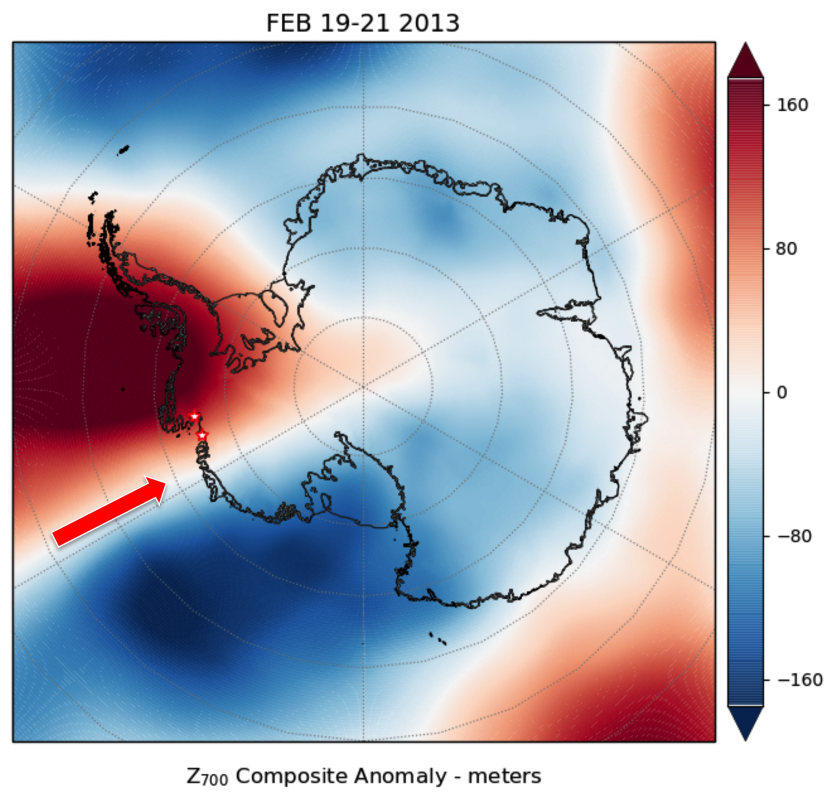

Figure 10. Composite anomaly of ERA5 $700 \mathrm{hPa}$ geopotential height for 19-21 February 2013. The red stars depict the locations of Pine Island and Thwaites glaciers. The red arrow depicts the direction of $700 \mathrm{hPa}$ winds relevant to the case study.

a thermal blanketing effect that is initiated in the first $2 \mathrm{~d}$ by a cloud radiative warming and then sustained for another $2 \mathrm{~d}$ by elevated SH flux.

\subsection{West Antarctica and Ross Ice Shelf December 2011}

We now consider a meteorological event that triggered surface melting at all three regions considered in this study. In late December 2011, a low-pressure system (Fig. 14) propagated eastward over the Ross Sea as a ridge of high pressure built over the Amundsen-Bellingshausen seas. This conjunction favored an intrusion of a warm, moist air mass far into the interior of West Antarctica. The marine air intrusion maintained an optically thick liquid cloud presence over the ASE region, where surface melting first began and signatures of surface snow melt persisted for several days. After crossing over the WAIS, the air mass then descended onto the Ross Ice Shelf, producing widespread föhn effects over Siple Coast. Relatively weak melt signatures were observed at Siple Dome. Föhn warming was most pronounced parallel to the Transantarctic Mountains in association with a summertime Ross Ice Shelf airstream event. This gave rise to melting at the Tom and Sabrina automatic weather stations.

At Pine Island and Thwaites glaciers the melt period of interest is between 19-25 December (Fig. 15), and on 20 and 21 December most satellite $T_{\mathrm{b}}$ measurements are consistent with unambiguous surface melt (also see Appendix B). Examining the surface emissivity samples (Fig. 15b) we see considerable spatial variability throughout the month. Between 2-18 December some of the grid cells show surface emissivity in the dry snow range $(<0.80)$, while others are in a range ( $>0.80$ ) that may signify wet or otherwise altered firn (e.g., Mätzler, 1987). We notice in Fig. 15a that the top of the $T_{\mathrm{b}}$ range in all days between 1-18 December is near or 

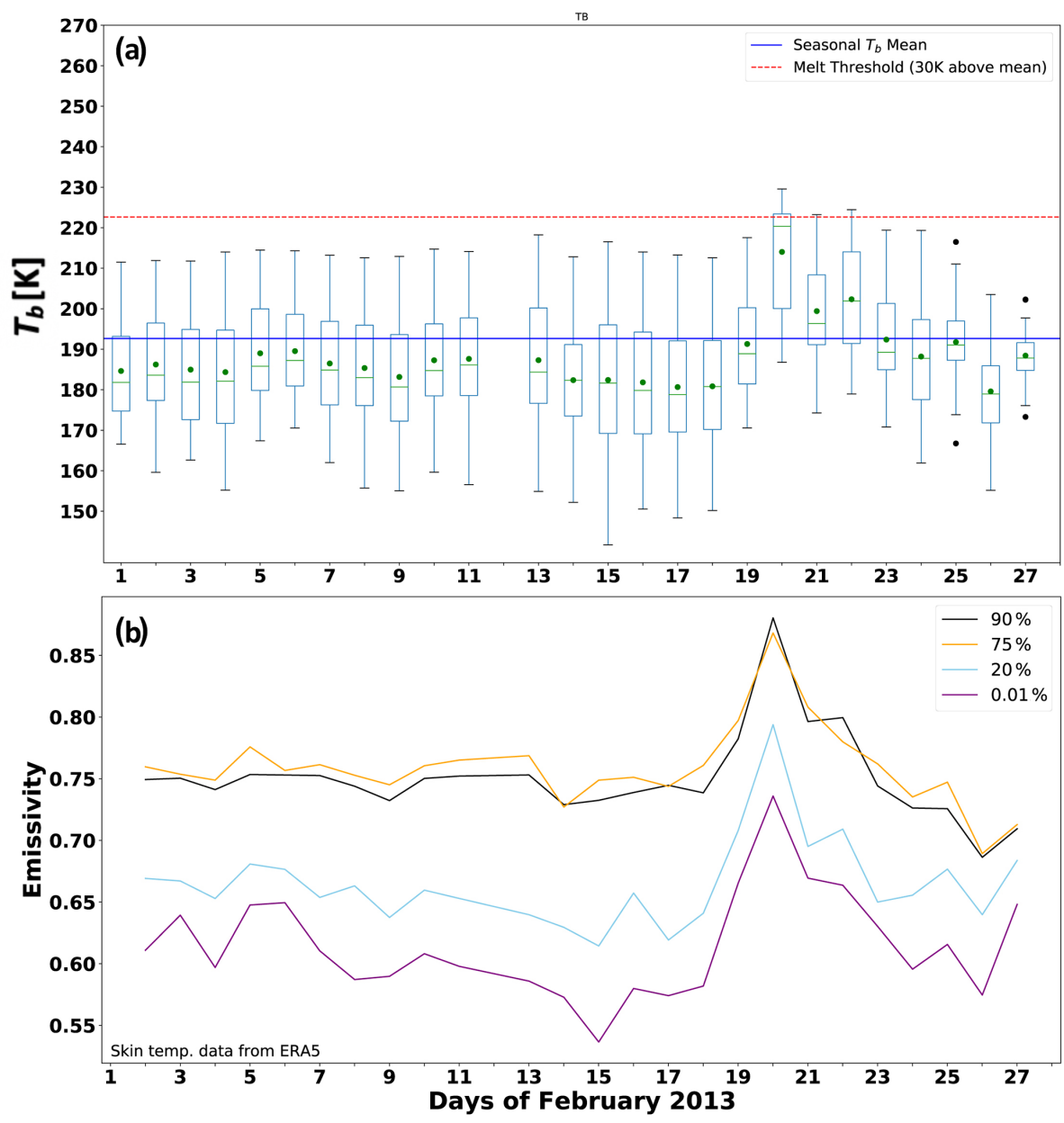

Figure 11. As in Fig. 3 but over the Pine Island and Thwaites Glacier region throughout February 2013. The five estimates of surface emissivity sampled in panel (b) from the region are referenced to the maximum $T_{\mathrm{b}}$ value in the region on 20 February.

slightly above the standard $30 \mathrm{~K}$ melt detection threshold. In Fig. $15 \mathrm{~b}$ the sampled percentiles are referenced to the maximum $T_{\mathrm{b}}$ on 21 December. We notice that the sampled grid cells reaching the 75th and 99th percentiles had very low surface emissivity earlier in the month. Figure $15 \mathrm{~b}$ therefore illustrates complexity in local-scale surface properties at these low-elevation locations near the coast. This complexity might arise from repeated melting and re-freezing episodes, combined with more intense episodes of precipitation, as well as varying topography especially near Pine Island and Thwaites glaciers.

Over Siple Dome this synoptic condition led to several satellite $T_{\mathrm{b}}$ measurements in the $>30 \mathrm{~K}$ threshold melt detection range between 22-26 December 2011 (Fig. 16), a less pronounced melt signature than in January 2015 but nevertheless detectable. In Fig. 16b, we again see spatial uniformity in sampled surface emissivity throughout the prior 3 weeks; then during the melt period of interest, some surface emissivity values remain low and within the dry surface range (e.g., Mätzler, 1987) while others become elevated by as much as 0.16 . At our location on the RIS adjacent to the Transantarctic Mountains (Fig. 1), Fig. 17a indicates that between 23-25 December some grid cells show a strong satellite PMW melt signature, and a few continue to show a melt signature as late as 27 December. Similar to Siple Dome, surface emissivity is spatially uniform and consistent with a dry snow surface throughout the previous 3 weeks of December (Fig. 17b).

Examining the ME components at these three locations reveals contrasting mechanisms for inducing and sustaining surface melt. At Pine Island and Thwaites glaciers during 1925 December the radiative fluxes (Fig. 18a and b) are consistent with optically thick clouds attenuating the SW flux and driving the new LW flux to nearly zero, particularly on 20 and 21 December and 23 and 24 December. The SH flux (Fig. 18c) is small but positive over two diurnal cycles 19 and 20 December, but this is partially offset by negative $\mathrm{LH}$ fluxes, such that the net turbulent flux (Fig. 18c) drops below zero every day between 19-25 December (and throughout the month). The total ME $>0$ across the diurnal cycles 

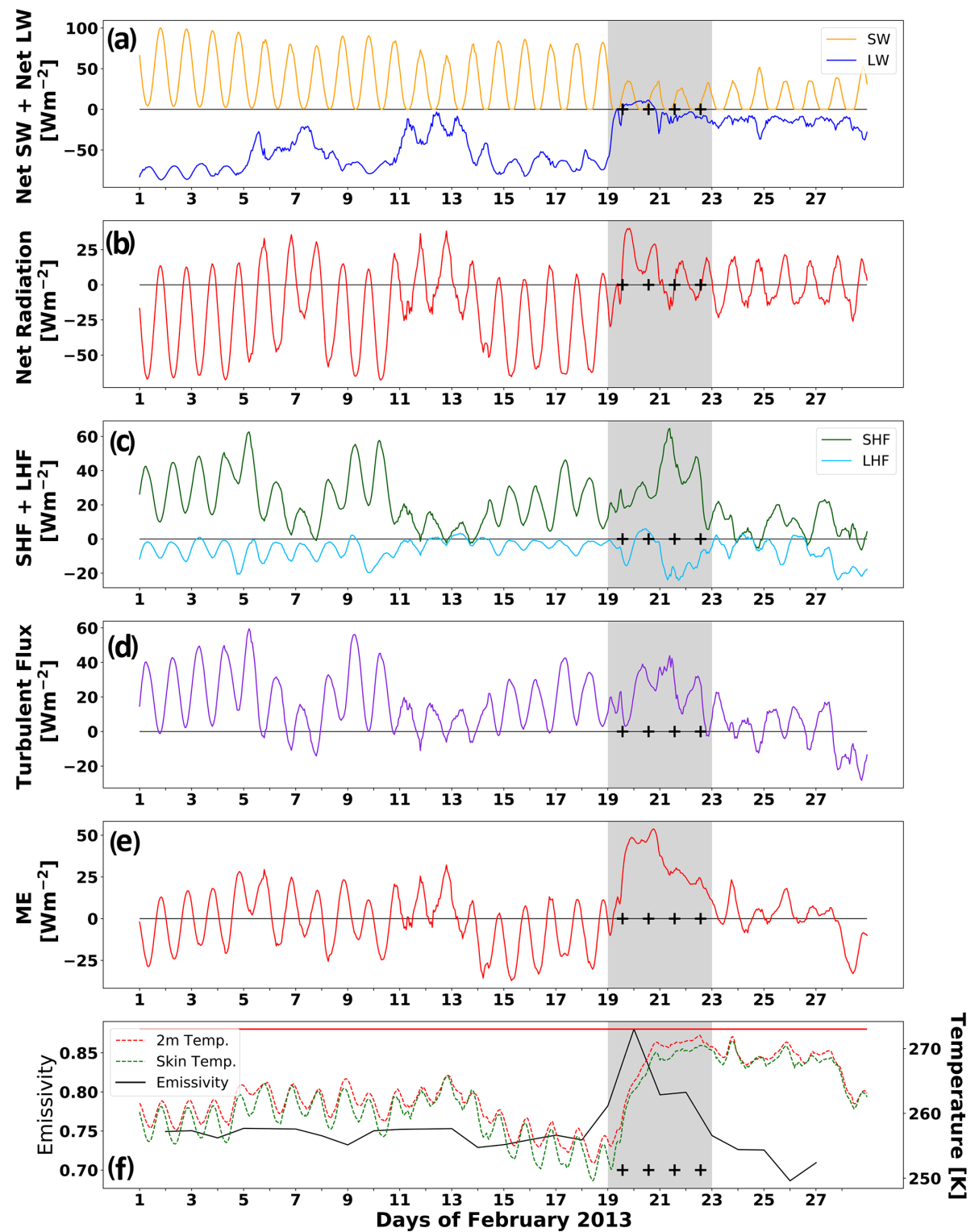

Figure 12. As in Fig. 4 but over the Pine Island and Thwaites Glacier region throughout February 2013.

20-22 December and 23 and 24 December, mainly due to the impact of cloud cover on the radiative fluxes (Fig. 18e). This induces steadily rising $2 \mathrm{~m}$ air and skin temperatures (Fig. 18f), with a corresponding rise in the fraction of grid cells showing satellite melt detection signatures (Fig. 15a).

Examining the SEB components at Siple Dome, we see that cloud radiative effects (Fig. 19a and b) do not substantially alter the SEB until late in the melt period of interest (22-26 December). This melt event instead appears to be induced and dominated by an impulse of SH flux that begins on 19 December (Fig. 19c), associated with the warm air intrusion, and causes the net turbulent flux (Fig. 19d) and the total ME (Fig. 19e) to remain positive through two diurnal cycles before the satellite PMW data show signs of surface melt.
During the satellite melt detection period, the ME actually drops below zero at the lowest Sun elevations, even as the ERA5 $2 \mathrm{~m}$ air and skin temperatures rise steadily (Fig. 19f).

At the RIS location the relevant energy inputs appear to precede the satellite melt signature detection by approximately $2 \mathrm{~d}$ (similar to Siple Dome). For the SEB components (Fig. 20) we have identified the study period of interest as 19-23 December, while the satellite melt signature occurs mainly on 23 December and later. The radiative fluxes during 20-22 December (Fig. 20a) show net SW attenuation and LW increases toward zero that appear consistent with allwave enhancement from optically thin cloud. During this interval the net radiative flux is mostly positive but does briefly drop to zero each diurnal cycle (Fig. 20b). A strong impulse 

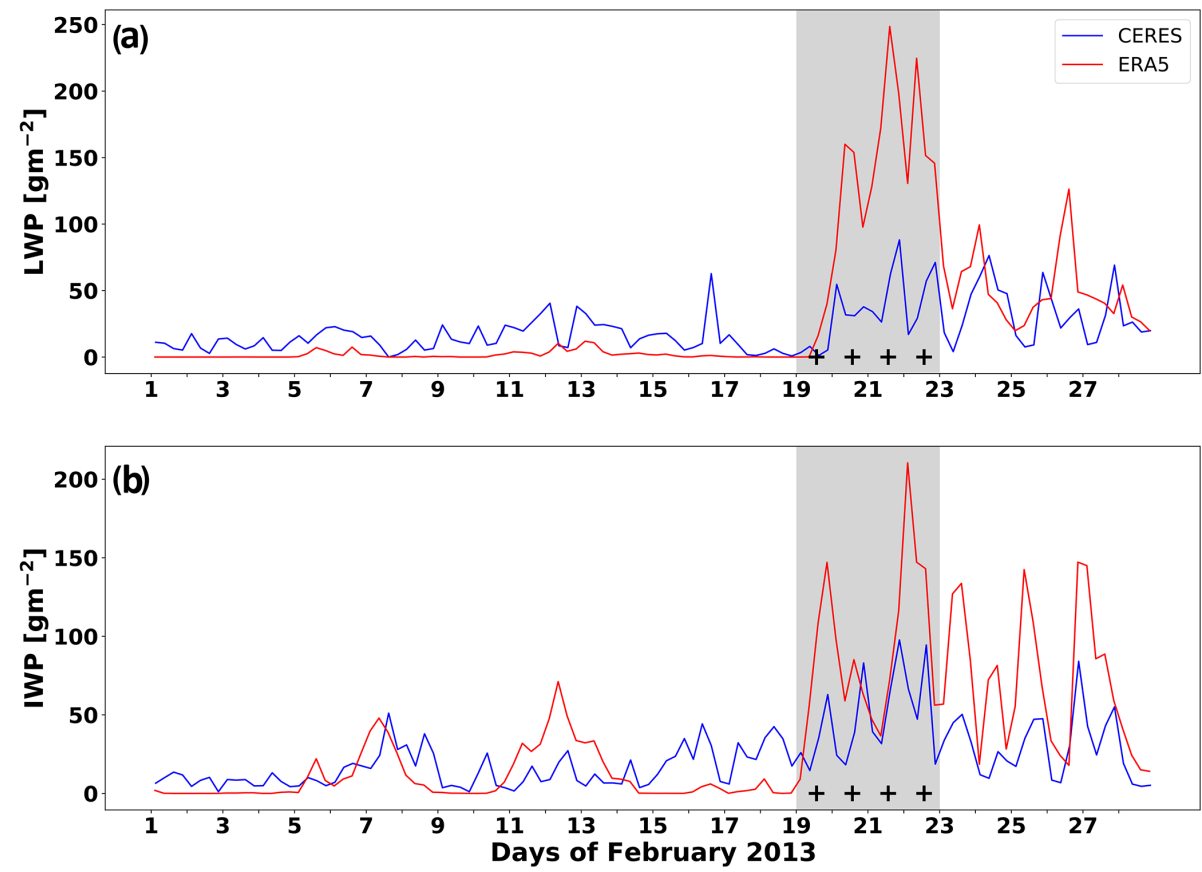

Figure 13. As in Fig. 5 but over the Pine Island and Thwaites Glacier region throughout February 2013.

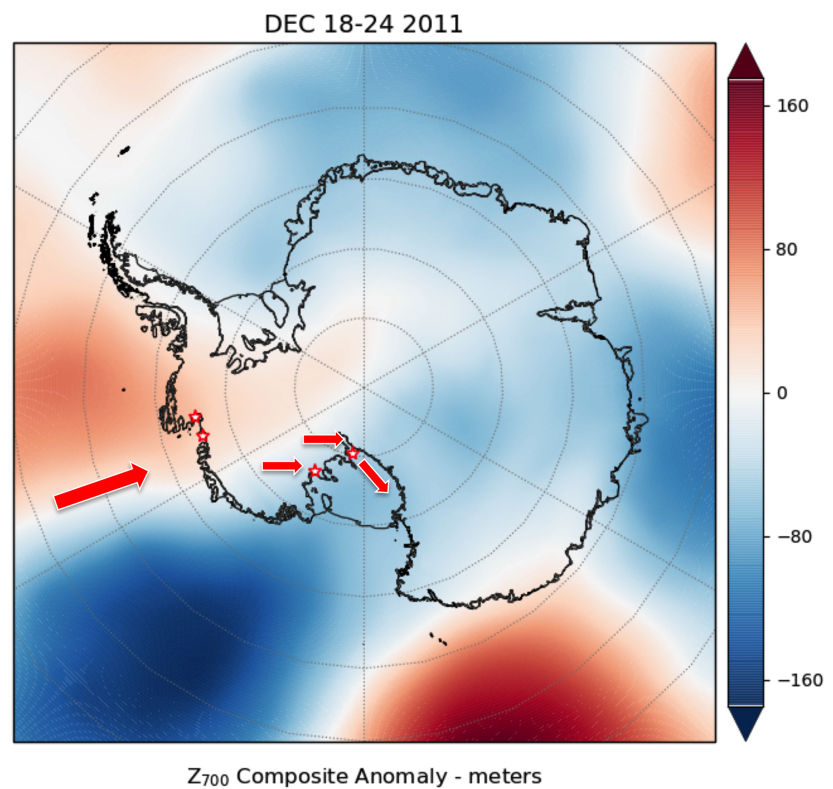

Figure 14. Composite anomaly of ERA $700 \mathrm{hPa}$ geopotential height for 18-24 December 2011. The red stars depict the locations of all three case study locations. The red arrows depict the direction of $700 \mathrm{hPa}$ winds relevant to the case study.

of positive SH flux (Fig. 20c) is partly canceled by a LH flux of opposite sign, but the net turbulent flux is positive across two diurnal cycles on 20 and 21 December (Fig. 20d), as is the total ME (Fig. 20e). This signature, positive SH and negative LH fluxes, is frequently indicative of föhn wind condi- tions (e.g., Kuipers Munneke et al., 2012b, 2018; Datta et al., 2019; Elvidge et al., 2020). The maximum in ME on 21 December corresponds with a local maximum in $2 \mathrm{~m}$ air and skin temperatures (Fig. 20f), which increased by nearly $10 \mathrm{~K}$ until they are close to freezing. The ERA5 daily maximum in $2 \mathrm{~m}$ air temperature continues to rise to above freezing on the 24th and peaks on the 25th before returning to sub-zero temperatures.

The cloud properties at Pine Island and Thwaites glaciers (Fig. 21) show impulses of high LWP and IWP simultaneously detected in CERES remote sensing data and simulated by ERA5. The LWP simulated by ERA5 is twice as large as that retrieved by CERES, and the radiative transfer model providing the fluxes in Fig. 18a and b responds to this high LWP. The IWP is consistent between ERA5 and CERES, but we note that both could be artifacts: the ERA5 values might be an overestimate per Silber et al. (2019), and the CERES retrievals could also be an overestimate based on occasional difficulties in phase discrimination when using MODIS spectral reflectances (e.g., Platnick et al., 2017). Nevertheless, the information within the melt period of interest in Fig. 13, specifically the total cloud water path (liquid plus ice), is highly consistent with optically thick clouds that provide most of the thermal blanketing effect in this case study. A field camp on Pine Island Glacier recorded mostly few and scattered clouds between 20-27 December. The timing of the two periods of increased sky coverage is consistent with the maxima in LWP and IWP of Fig. 13. Late on 20 December and early on 21 December, the sky became broken to overcast with cloud base at $1800 \mathrm{~m}$. During 24 December the 


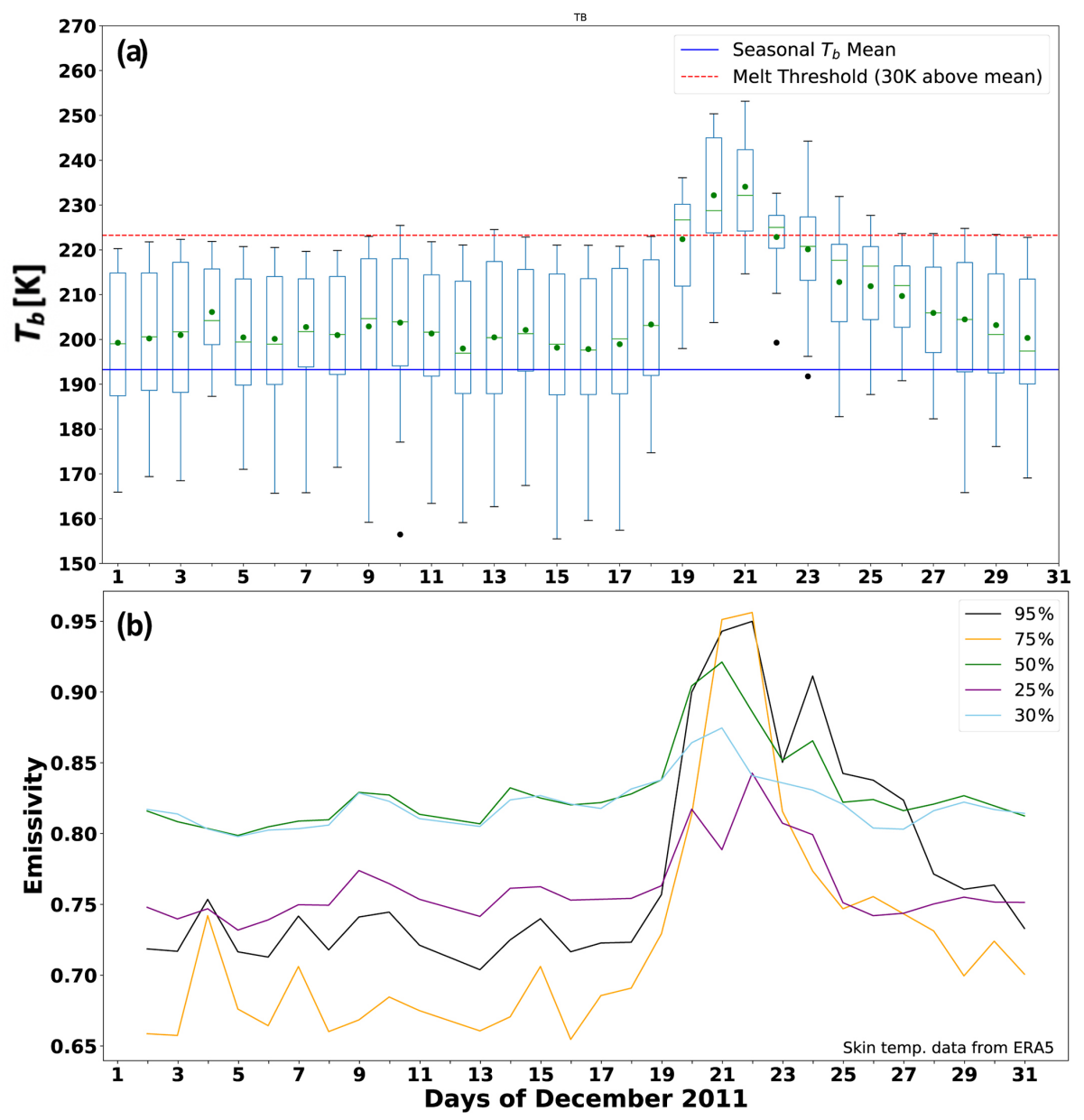

Figure 15. As in Fig. 3 but over the Pine Island and Thwaites Glacier region throughout December 2011. The five estimates of surface emissivity in panel (b) sampled from the region are referenced to the maximum $T_{\mathrm{b}}$ value in the region on 21 December.

visibility dropped to $100-800 \mathrm{~m}$ in freezing fog and blowing snow. These observations do not definitively indicate optically thick clouds, and it is possible that this specific field camp location had lighter cloud cover than average for the entire region considered in this case study.

At Siple Dome the cloud properties (Fig. 22) during the melt period of interest are comparable with the rest of the month, with average LWP values between 21-25 December of 14 and $5 \mathrm{~g} \mathrm{~m}^{-2}$ from CERES and ERA5, respectively, and corresponding average IWP values of 14 and $19 \mathrm{~g} \mathrm{~m}^{-2}$ from CERES and ERA5, respectively. After 25 December there is an impulse of LWP $>80 \mathrm{~g} \mathrm{~m}^{-2}$ that is simulated by ERA5 $2 \mathrm{~d}$ before it is detected in the CERES MODIS-based remote sensing data. This cloud intrusion having moderate to large optical thickness may help explain the skin and $2 \mathrm{~m}$ air temperatures between 27 and 28 December, which are very close together, at or just below freezing, and at monthly maximum values. Overall, this case study suggests a thermal blanketing episode at Siple Dome driven primarily by a positive SH flux impulse that began on 19 December, that caused a delayed melt onset as detected by satellite PMW data $3 \mathrm{~d}$ later, and that may have been prolonged by a cloud radiative effect 5$7 \mathrm{~d}$ later. The slow melt onset may be the result of smaller total ME during 21-25 December, including the drops below zero, as compared with all the other cases considered in this work. Field camp observations at Siple Dome indicate cloud cover ranging from scattered to overcast between 2225 December, with most observations also showing reduced visibility in freezing fog, drifting snow, or blowing snow. On 24 December an overcast layer is noted at 23:50 UTC with cloud base at $1400 \mathrm{~m}$ and light snowfall. Throughout 26 December the ceiling is obscured by mist, freezing fog, or drifting snow. On 27 December low cloud and overcast conditions are recorded throughout most of the day with cloud base $\sim 300 \mathrm{~m}$. These observations are qualitatively consistent with the radiative flux components of Fig. 19a and b and the cloud properties of Fig. 22.

At the RIS location cloud properties between 19-23 December (Fig. 23) show ERA5 simulated and CERES detection of cloud cover that are consistent in time and subject 

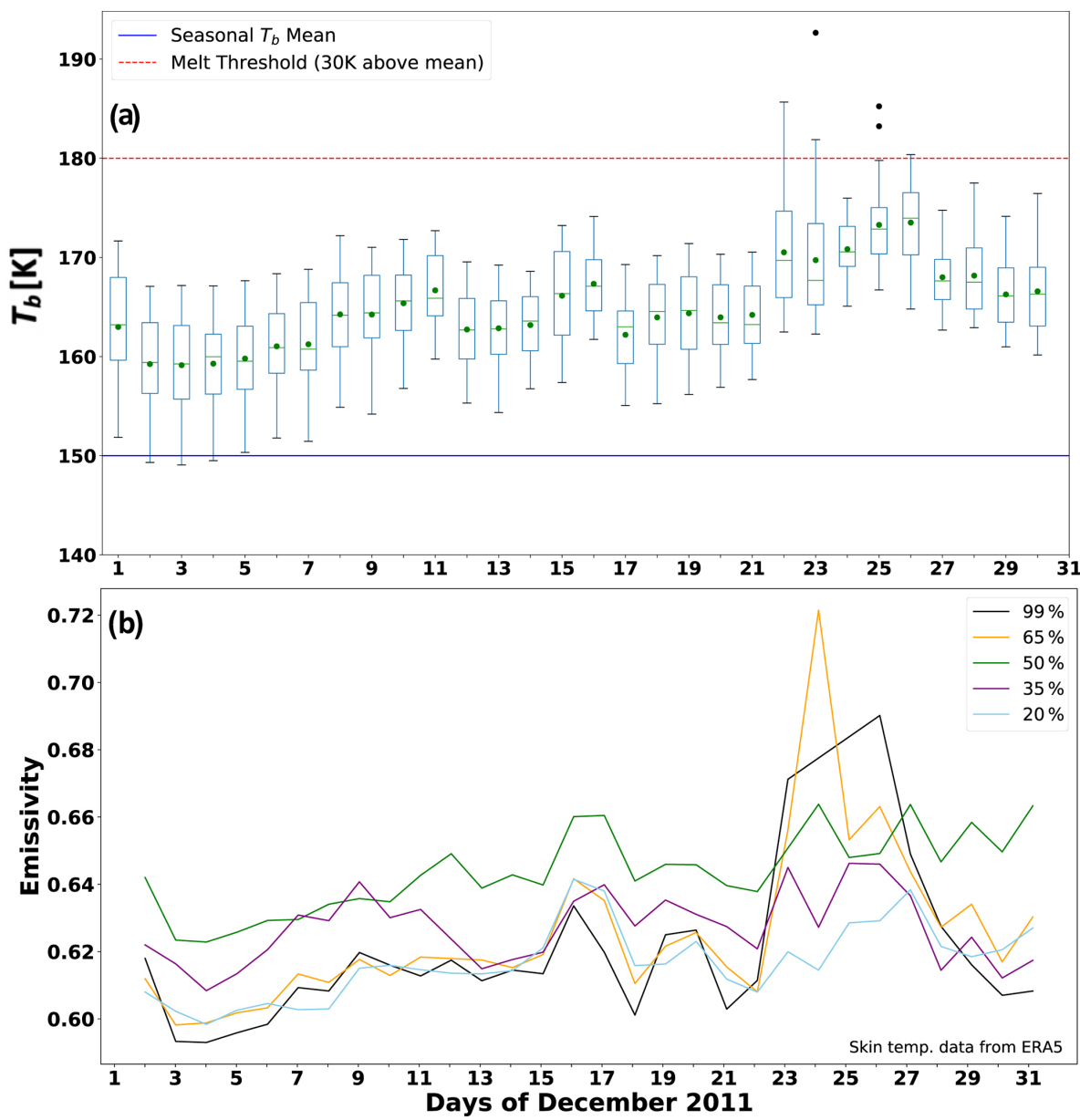

Figure 16. As in Fig. 3 but over the Siple Dome region throughout December 2011. The five estimates of surface emissivity in panel (b) sampled from the region are referenced to the maximum $T_{\mathrm{b}}$ value in the region on 23 December.

to the same potential uncertainties and errors as in the previous case studies. With CERES LWP and IWP values of $14.7 \pm 11.0$ and $32.7 \pm 16.1 \mathrm{~g} \mathrm{~m}^{-2}$, respectively, the clouds are likely to be optically thin and cause an all-wave radiative enhancement. Here we should consider the possibility that the clouds might be optically thin in part due to a cloudclearing effect of the föhn wind; the other two locations during late December 2011 saw optically thicker clouds during the surface melt conditions.

We now examine the local-scale meteorology at the RIS location in more detail to illustrate the föhn wind effect. Figure 24 shows ERA wind speed and direction at the surface and at $850 \mathrm{hPa}$. Between 9-19 December winds are light to moderate and have a variety of directions but are mostly northerly between 9-14 December and 18 and 19 December. During the melt period 23-25 December, surface and lower troposphere winds strengthen, and their directions become more spatially uniform, mainly easterly to southeasterly, consistent with descent into the region from the Transantarctic Mountains.
In Fig. 25 we examine in situ measurements of $2 \mathrm{~m}$ air temperature, relative humidity, wind speed, and wind direction from the Tom and Sabrina AWSs. During the time intervals 9-19 December and 19-23 December, these measurements are very consistent with the ERA5 values (Figs. 20 and 24). Between 19-23 December, the two local maxima in wind speed (Fig. 25c) correspond to minima in relative humidity (Fig. 25b), along with a slight westward shift in wind direction (Fig. 25d), and these changes are consistent with föhn wind occurrence. However, between 23-26 December surface wind speed is consistently stronger, and wind direction is more consistently southeasterly at both AWSs than in the ERA5 reanalysis data, although the $2 \mathrm{~m}$ surface air temperatures compare well. A possible cause of this discrepancy might be the coarse spatial resolution in ERA5, yielding an underprediction of föhn winds (e.g., Trusel et al., 2013). The ERA5-based analysis (Figs. 20 and 23) suggests that the initial föhn wind onset combined with a cloud radiative enhancement gradually set up the conditions starting on $20 \mathrm{De}$ cember that lead to satellite PMW melt signature detection on 23 December. Absent the cloud radiative enhancement af- 


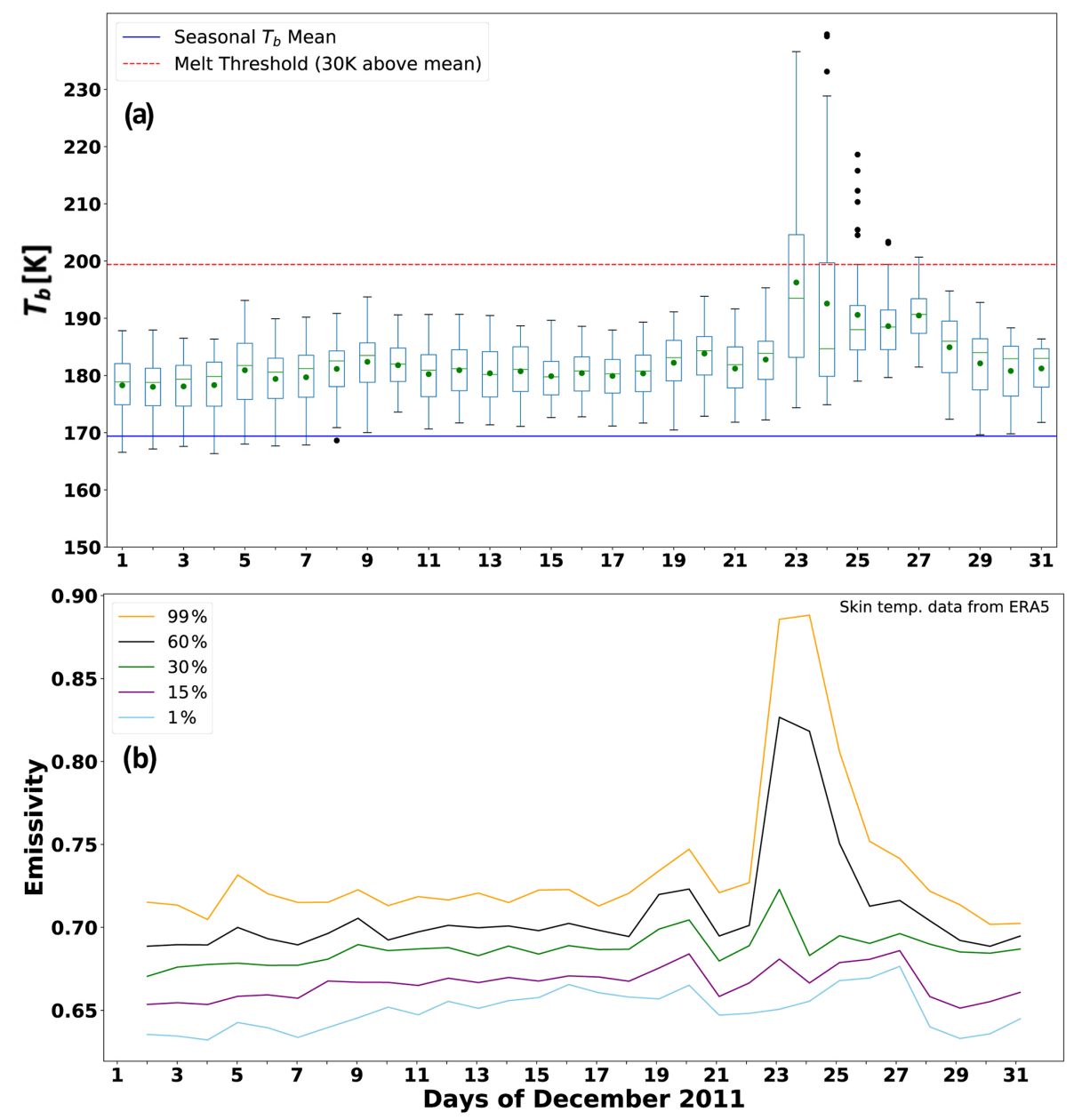

Figure 17. As in Fig. 3 but over the RIS region containing the Tom and Sabrina AWSs throughout December 2011. The five estimates of surface emissivity sampled in panel (b) from the region are referenced to the maximum $T_{\mathrm{b}}$ value in the region on 23 December.

ter 22 December, the AWS data suggest that persistent föhn winds alone can sustain the surface melt conditions for several more days. We do note that the underprediction of föhn winds in ERA5 might be offset by larger LWC and IWC that are retrieved in the CERES data (Fig. 23).

Finally, we note that between 1-9 December there are strong surface and lower troposphere winds from a southeasterly direction, seen in both ERA5 and AWSs, that induce consistently positive SH flux and positive net turbulent flux over at least three diurnal cycles. These observations would also be consistent with föhn winds from the Transantarctic Mountains. Skin temperatures and $2 \mathrm{~m}$ air temperatures are also 3-5 $\mathrm{K}$ warmer than during the subsequent time interval 9-19 December. However, cloud cover appears to be consistently light in both the ERA5 simulations and CERES retrievals (Fig. 23), which allows for LW cooling (Fig. 20a), and the total ME remains mostly negative before 19 December. Early in December the synoptic conditions discussed above have not yet set up the warm air intrusion that brings moisture and cloud cover to all three locations. A downslope wind by itself may not be sufficient to cause a detectable surface melt event (e.g., King et al., 2017) but may need to operate in conjunction with additional conducive atmospheric conditions.

\section{Conclusions}

In this study we demonstrate that readily available climatic data, including meteorological reanalysis and satellite remote sensing, can be used to examine and diagnose individual episodes of surface melt over Antarctic ice sheet and ice shelf locations that are of significant concern in a steadily warming climate. We demonstrate examples for each of three thermodynamic mechanisms that induce surface melting. The case study from January 2015 over Siple Dome very likely involves the same all-wave cloud radiative enhancement discovered over the GIS (Bennartz et al., 2013; Van Tricht et al., 2016). In contrast, Pine Island and Thwaites glaciers during December 2011 experience a thermal blanketing effect where 

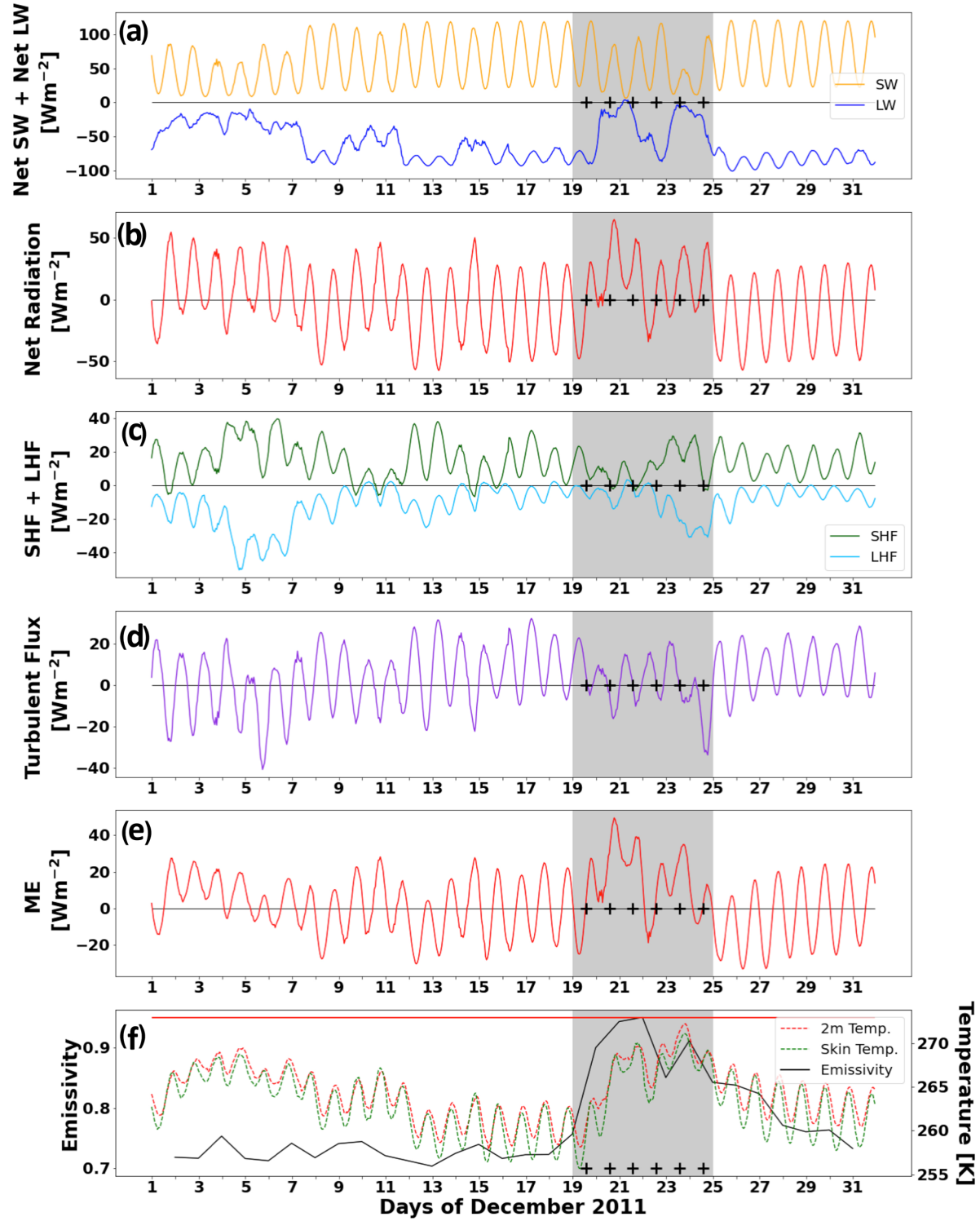

Figure 18. As in Fig. 4 but over the Pine Island and Thwaites Glacier region throughout December 2011.

the positive ME impulse comes mainly from optically thick clouds. Over the Tom and Sabrina AWS locations on the RIS, we identified a föhn wind effect that might be augmented by an all-wave cloud radiative enhancement. Other examples when two of the mechanisms are at work include the December 2011 thermal blanketing case over Siple Dome, where an impulse of positive SH flux sets up the surface conditions for melt onset followed by additional energy input from a cloud radiative enhancement, and the February 2013 thermal blanketing case over Pine Island and Thwaites glaciers, when optically thick cloud cover initiates a melt event that is subsequently prolonged by positive SH flux.

For the Pine Island and Thwaites Glacier region we notice considerable local-scale variability in surface $T_{\mathrm{b}}$ and emissivity, possibly related to microwave signatures dominated by new snow in some grid cells and by older snow or prior melt events in others. Bell et al. (2017) show that local-scale variability on Antarctic ice shelves influences whether surface meltwater filters into the ice as a source or hydrofracturing or runs off in temporary rivers. Local-scale spatial inhomogeneity on the ice shelves probably requires further investigation to make reliable projections regarding multi-year stress.

Two limitations stand out with the present level of analysis. First, improvements are needed in cloud microphysics and related optical properties in both the reanalysis models and in the satellite remote sensing retrievals. AWARE ground-based remote sensing data have fostered some progress in this respect, in providing confidence in MODIS retrievals of cloud microphysical properties (Wilson et al., 2018), and in providing unique data for modeling case 

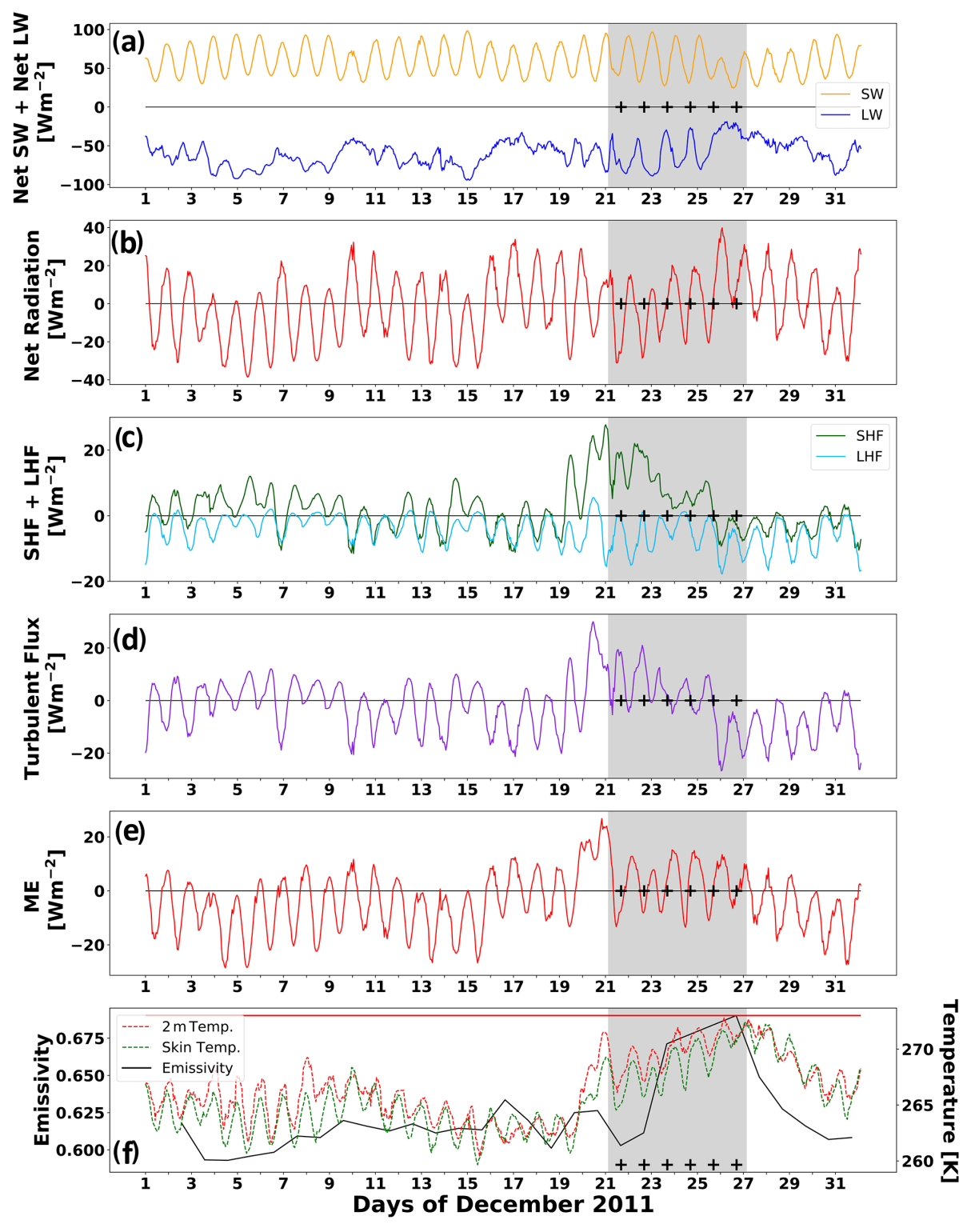

Figure 19. As in Fig. 4 but over the Siple Dome region throughout December 2011.

studies (Hines et al. 2019; Silber et al., 2019; Lubin et al., 2020). Presently throughout the ASE, although the presence of cloud in a case study is reliably detected, the microphysical uncertainties sometimes prevent a full diagnosis of the melt event mechanism. For example, in the January 2012 case study over Pine Island and Thwaites glaciers, a cloud radiative effect is clearly indicated, but it is not clear if this is a thin cloud all-wave effect or an optically thick thermal blanketing effect. In atmospheric models, the use of doublemoment cloud microphysical parameterizations makes noticeable improvements over Antarctica (e.g., Hines et al., 2019). However, these more rigorous parameterizations are found mainly in global climate models. Numerical weather prediction models, which are used to generate reanalysis data, must run on an operational forecast schedule and may not be able to accommodate the time-consuming rigorous parameterizations.

We mention that one regional model is known to be useful for this type of work. This is the European Regional Atmospheric Climate Model second version (RACMO2; van Wessem et al., 2018). Lenaerts et al. (2018) used RACMO2 to accurately simulate West Antarctic melt events between 1979-2015. In RACMO2, van Wessem et al. (2014) addressed the common cloud LWP deficiency over Antarctica by altering the model cloud microphysics to allow for more extensive cloud liquid water transport. This is done primarily by making simple but defensible adjustments to the threshold for ice supersaturation (Tompkins et al., 2007) and the criti- 

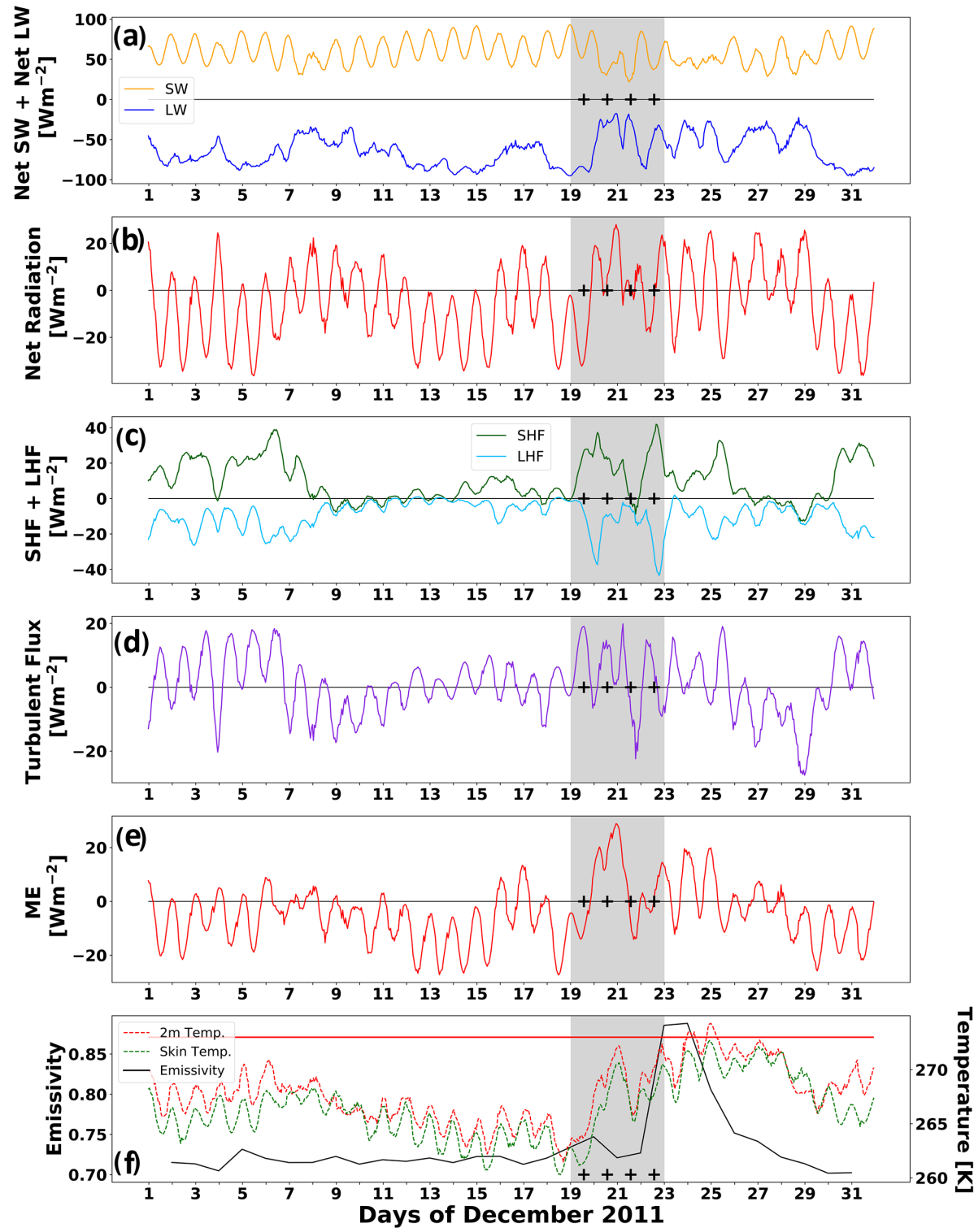

Figure 20. As in Fig. 4 but over the RIS region containing the Tom and Sabrina AWSs throughout December 2011.

cal cloud content for efficient precipitation (Lenaerts et al., 2018). While these simple alterations allow for sufficient cloud liquid water to contribute radiatively to positive ME and surface melt onset, the simulated LWP values have yet to be thoroughly validated against other data such as SYN1deg. It is therefore not clear if RACMO2 simulations by themselves can discriminate between the mechanisms involving optically thick vs. optically thin clouds, and supplementing RACMO2-based analysis with SYN1deg data is therefore recommended.

In the MODIS-based retrievals contained in the CERES SYN1deg data product, we suspect that some of the higher IWP values may actually be liquid water clouds. Chylek et al. (2006) suggest that cloud phase discrimination that re- lies on differential backscatter in MODIS near-infrared channels can be biased toward the ice phase. The MODIS retrieval algorithms for cloud phase discrimination generally use both near- and mid-infrared bands, and further investigation is needed specific to clouds over West Antarctica to identify possible errors. Additionally, the CERES-MODIS approach can retrieve unrealistically high IWP values over ice sheets, mainly over the Antarctic interior. An issue with this approach is that over these areas, where the contrast between the surface and cloud albedo is small, a large correction of cloud water path is necessary to match the TOA fluxes since they are insensitive to small changes. Furthermore, since LWP has limited observational constraints over Antarctica, the algorithm likely has to resort to increasing the 

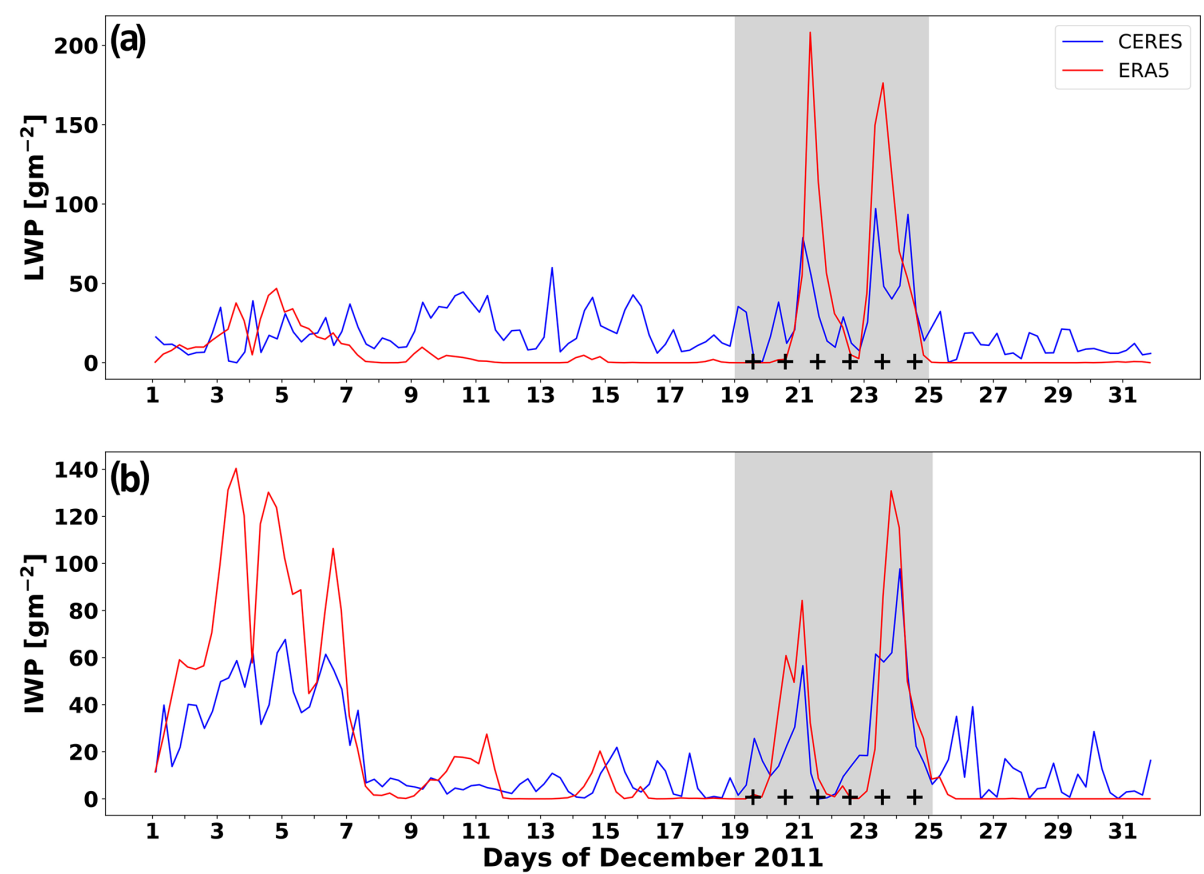

Figure 21. As in Fig. 5 but over the Pine Island and Thwaites Glacier region throughout December 2011.
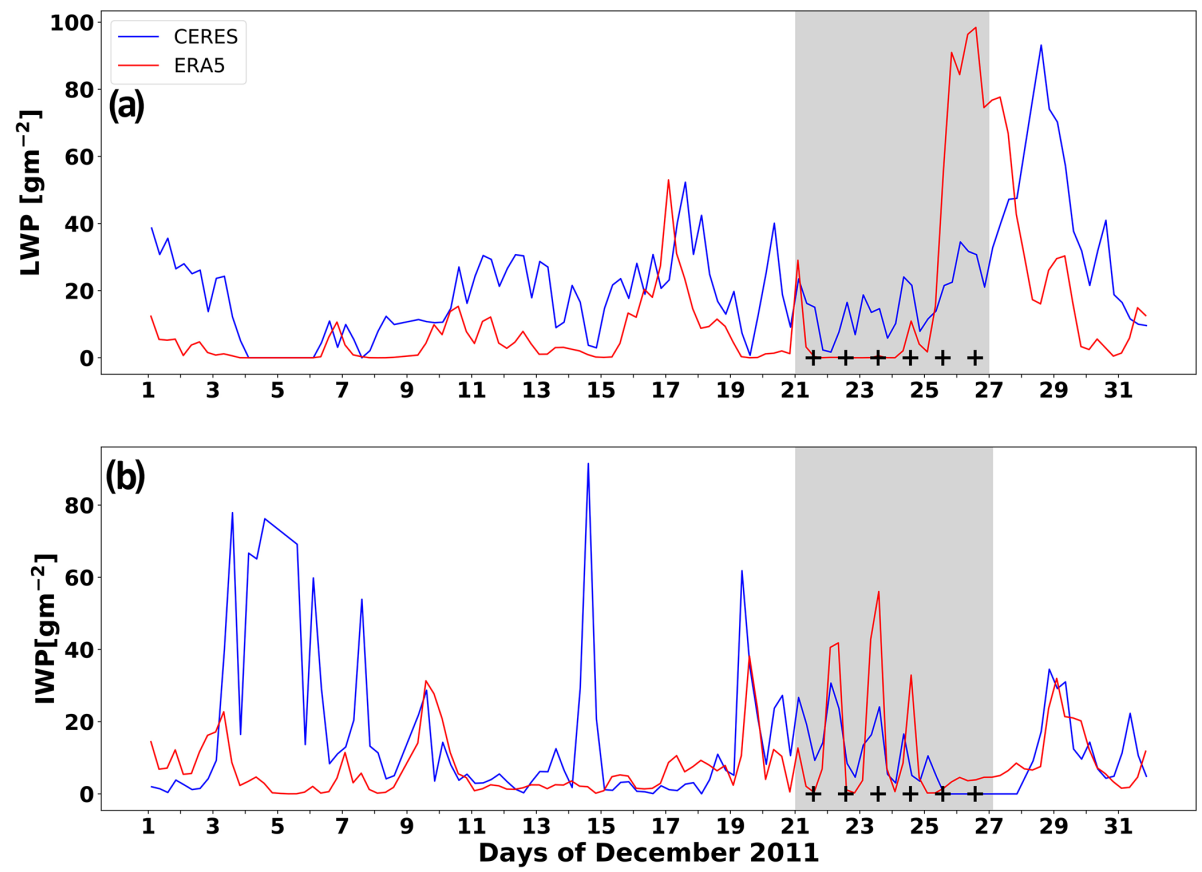

Figure 22. As in Fig. 5 but over the Siple Dome region throughout December 2011.

IWP dramatically to compensate for any lack of brightness owing to missing liquid (e.g., Lenaerts et al., 2017).

A second limitation involves quantifying the effect of föhn winds. In the RIS example the AWS data indicate more persistent föhn winds than are simulated by ERA5. This is most likely related to the coarse spatial resolution in the reanal- ysis model. While ERA5 can identify the likely presence of a föhn wind effect based on its generally accurate lower troposphere wind direction relative to varying high terrain, a more quantitative analysis might need to incorporate detailed knowledge of the actual terrain elevation (Dreschel and Mayr, 2008; Elvidge et al., 2015; King et al., 2017). 

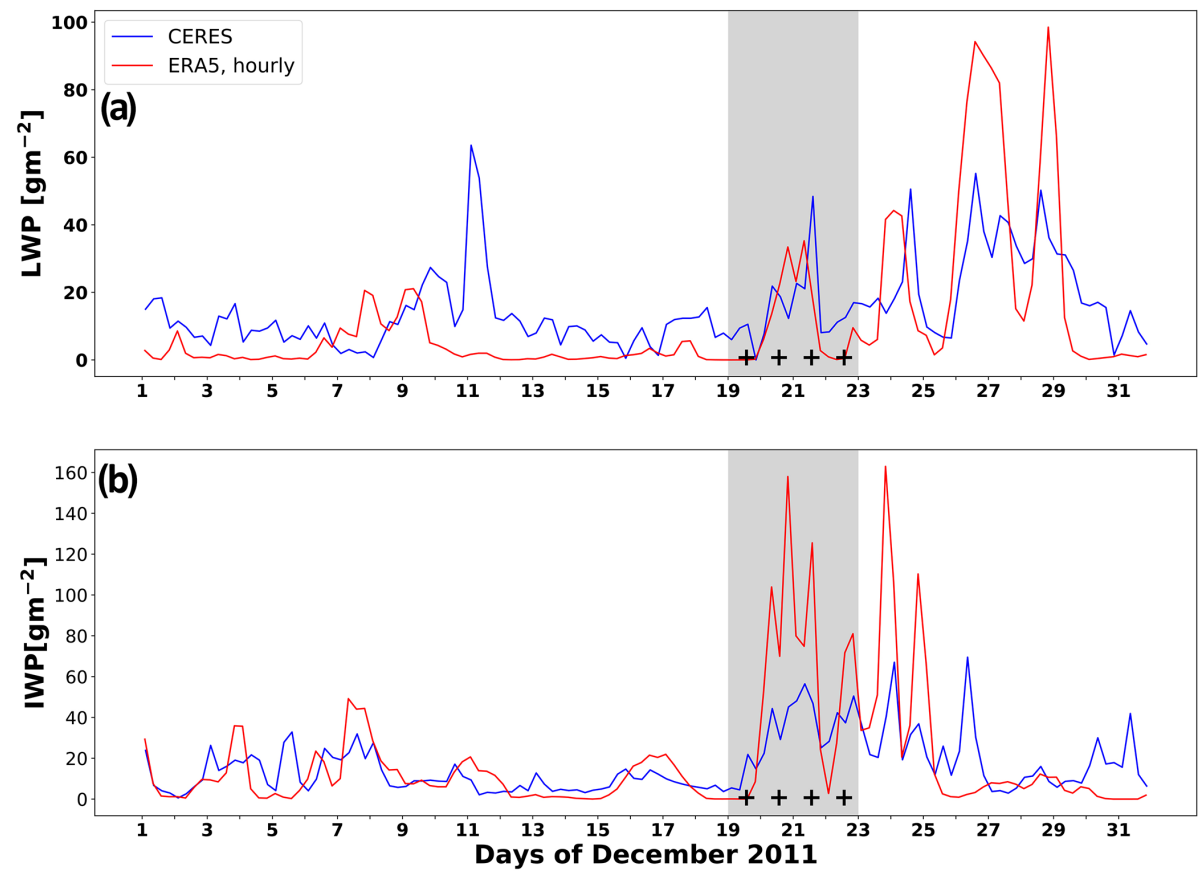

Figure 23. As in Fig. 5 but over the RIS region containing the Tom and Sabrina AWSs throughout December 2011.
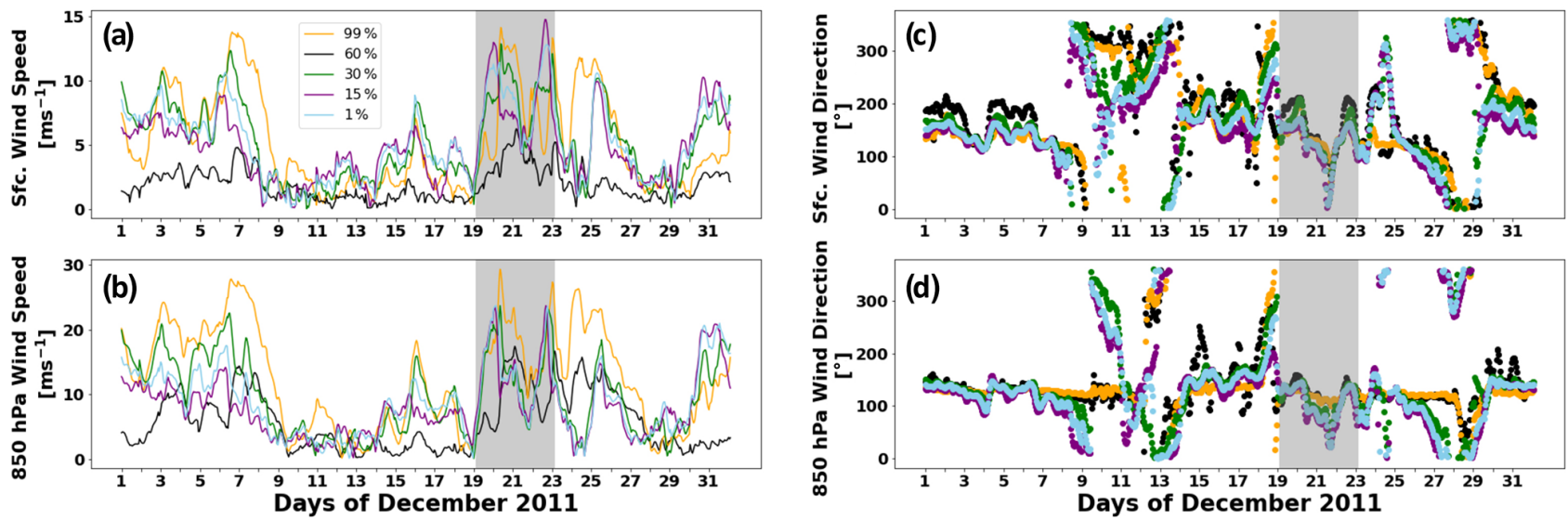

Figure 24. Time series of sampled ERA5 (a) near-surface wind speed, (b) $850 \mathrm{hPa}$ wind speed, (c) near-surface wind direction, and (d) $850 \mathrm{hPa}$ wind direction over the RIS region containing the Tom and Sabrina AWSs throughout December 2011. Percentiles sampled correspond to the locations of Fig. 18b.

Over the modern satellite record spanning nearly four decades, it should be possible to make projections regarding future atmospheric stress on the West Antarctic ice shelves by identifying the specific mechanisms, their frequency of occurrence singly or concurrently, their relationships with large-scale meteorological drivers (Nicolas and Bromwich, 2011; Scott et al., 2019), and transport and abundance of atmospheric precipitable water (e.g., Suzuki et al., 2013; Wille et al., 2019). The analysis methods presented here, in which the energetics of individual melt events are diagnosed from satellite observations and reanalysis data, can supplement recent large-scale analysis using regional modeling (e.g., Deb et al., 2018). Our individual cases and their meteorological drivers are qualitatively consistent with the large-scale modeling analysis of Deb et al. (2018). In conjunction with increasing understanding of shelf basal melting and its time variability (Adusumilli et al., 2020) and understanding of the disposition of surface meltwater either within the structure of Antarctic ice shelves or as runoff (e.g., Bell et al. 2017), one can also envision a quantitative assessment of ice shelf resilience in a warming climate based on analysis of the surface energy balance. 

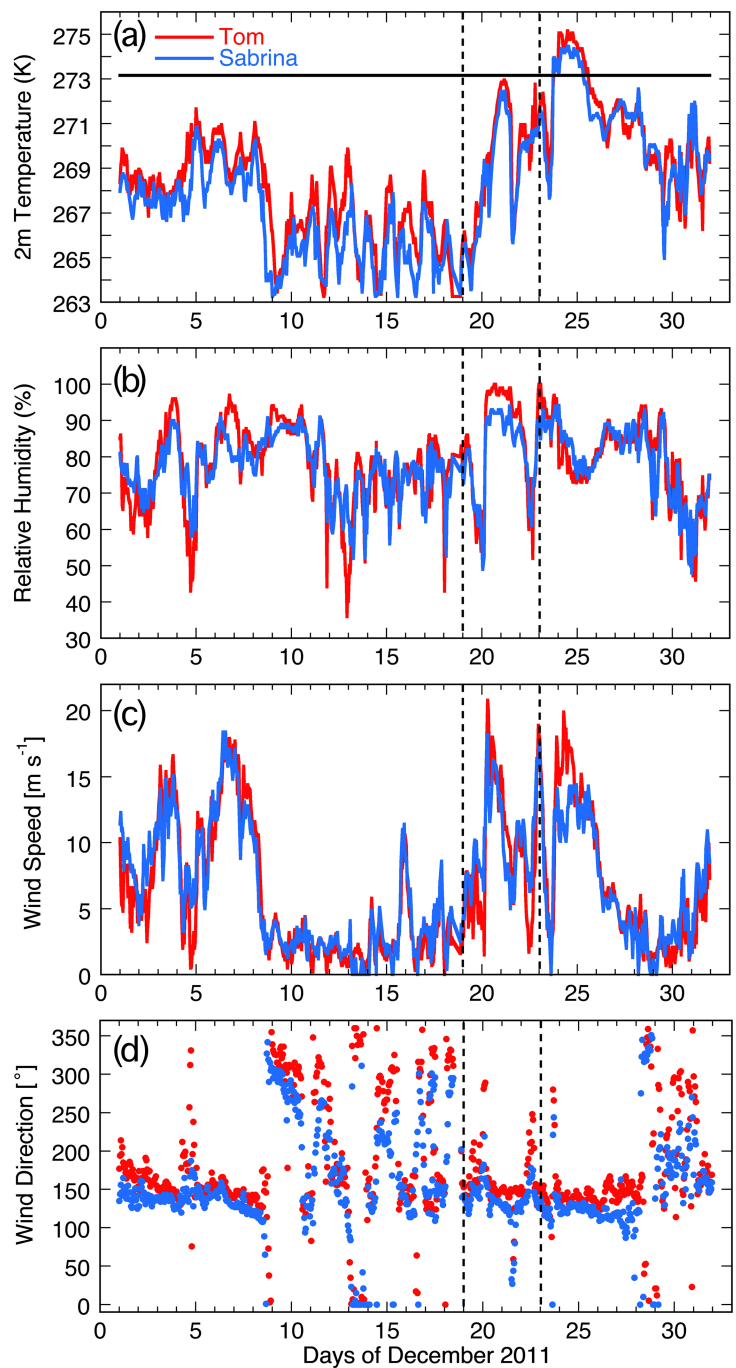

Figure 25. Time series of $2 \mathrm{~m}$ meteorological measurements from the Tom and Sabrina AWSs throughout December 2011: (a) air temperature, (b) relative humidity, (c) wind speed, and (d) wind direction. 
Appendix A: Supplementing ERA5 melt energy calculation with satellite-retrieved cloud microphysical properties

Silber et al. (2019) compared ERA5 data with AWARE data from the WAIS Divide ice camp and found a tendency for ERA5 to overestimate cloud ice water content and underestimate cloud LWP. We therefore compare the ERA5 skin temperature, downwelling SW flux, and downwelling LW flux with the AWARE measurements at WAIS Divide in Fig. A1 to estimate how errors in ERA5 cloud microphysics might impact a time series of the ME before and during a melt event. The AWARE flux measurements were made using the ARM user facility pyranometers and pyrgeometers (Mather and Voyles 2013; Lubin et al. 2020). Figure A1a shows that ERA5 consistently underestimates skin temperature, except on occasions when the Sun is at its lowest elevation, but that the temperature discrepancy varies from day to day. The instantaneous discrepancies between ERA5 and the measured downwelling SW flux (Fig. A1b) can sometimes be on the order of $100 \mathrm{~W} \mathrm{~m}^{-2}$, but the similarity in amplitudes of the diurnal cycles suggest that ERA5 is reliably simulating the presence of clouds on a daily basis. Much more striking discrepancies appear between ERA5 and measured downwelling LW flux (Fig. A1c). Here there are many periods, sometimes a day long, where ERA5 underestimates the LW flux by $\sim 50 \mathrm{Wm}^{-2}$, which would be expected if modeled LWP is too low (see Fig. 14 in Lubin et al. 2020). There are, however, other periods when the ERA5 and measured LW fluxes are consistent. This episodic nature of the LW flux discrepancies, in which errors can persist throughout a day, suggests that we should find alternative estimates of the cloud LWP and IWP to evaluate the realism of LW flux calculations in the ME based on ERA5 data.

Our goal is to be able to evaluate the energetics of surface melt events anywhere in Antarctica rather than be tied to the few instances such as AWARE where corroborating surface measurements are available. We therefore examine the contrasts between ERA5 and CERES SYN1deg cloud properties and radiative fluxes during the AWARE January 2016 melt event but at Siple Dome instead of WAIS Divide. From Nicolas et al. (2017) we know that clouds should be optically thick and that the ME should be positive over several diurnal cycles after 10 January 2016. Over Siple Dome during the melt event, both ERA5 and CERES indicate LWP $>50 \mathrm{~g} \mathrm{~m}^{-2}$ (Fig. A2). However, ERA5 cloud IWP is sometimes twice as large as the CERES retrieval.

If cloud microphysics are more realistic in the CERES data product, one might be tempted to calculate the ME by replacing ERA5 net radiative fluxes with their CERES counterparts, while retaining the ERA5 turbulent fluxes. We tried this approach for January 2016 over Siple Dome (Fig. A3), and the result is unsatisfactory. The diurnal amplitude of the CERES net SW flux is up to twice as large as that modeled by ERA5 and is also qualitatively less consistent with the
AWARE measurements from WAIS Divide. There are substantial differences of order $50 \mathrm{~W} \mathrm{~m}^{-2}$ between ERA5 and CERES net LW fluxes, with CERES appearing to be an improvement compared with ERA5's known tendency to underpredict the net LW flux over Antarctica (Silber et al., 2019). However, the ME calculation using ERA5 for all flux terms is basically realistic in that ME $>0$ over three diurnal cycles after 10 January and almost always drops below zero at the lowest Sun elevation for the rest of the month. When we substitute the CERES radiative fluxes, both the net $(\mathrm{SW}+\mathrm{LW})$ radiative flux and ME are positive over several diurnal cycles for about half the month, including before 10 January when we know that meteorological conditions were not conducive to surface melt (Nicolas et al., 2017). We therefore conclude that a mix-and-match approach to evaluating the ME is unsuitable, and this is not surprising given that ERA5 and CERES use different radiative transfer algorithms. Instead, we proceed by calculating the ME with ERA5 radiative and turbulent fluxes and then examine the CERES SYN1deg cloud LWP and IWP as a separate check on the realism of cloud properties simulated by ERA5. 


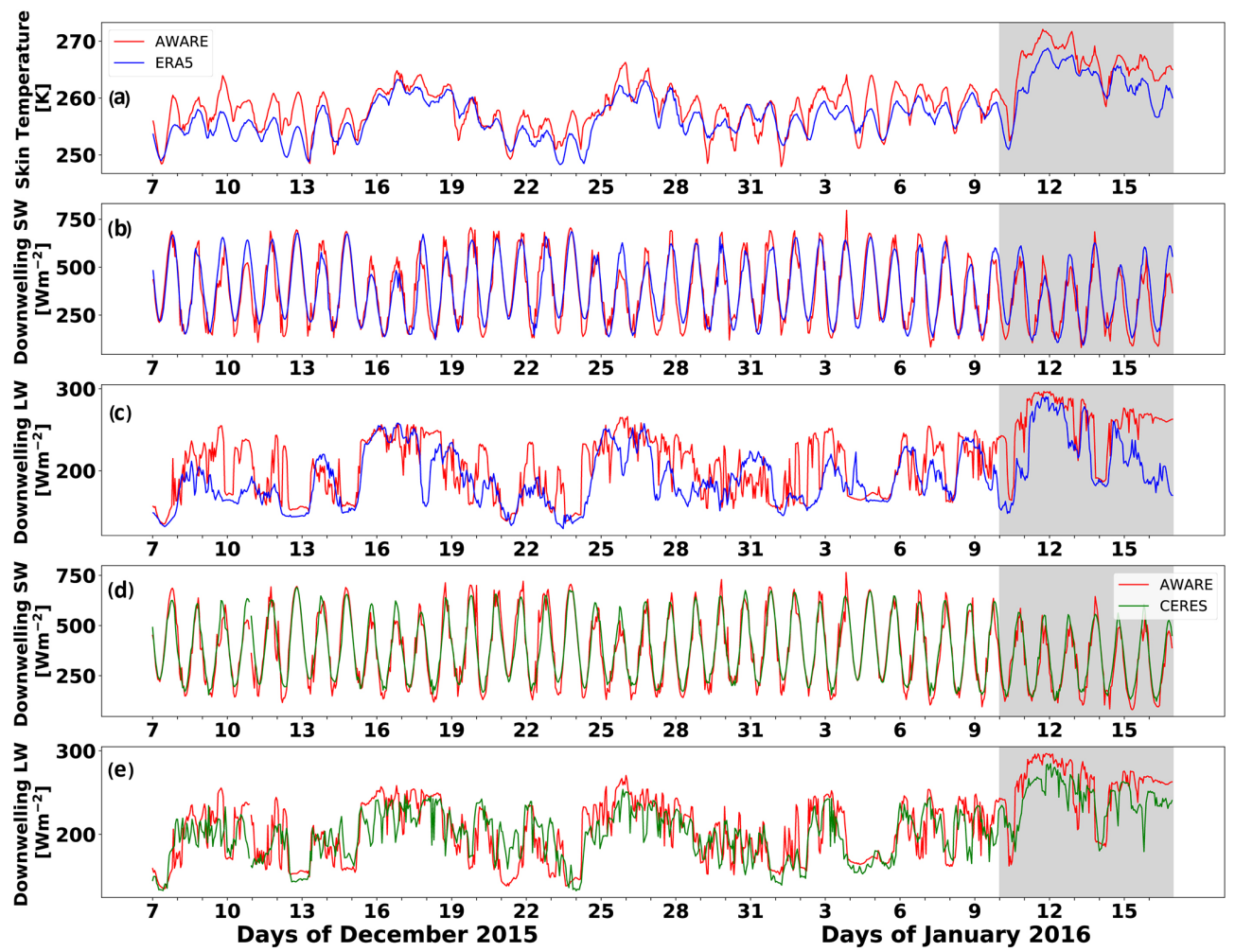

Figure A1. Time series comparison of hourly SEB components from ERA5 at the WAIS Divide ice camp with surface measurements from AWARE (Lubin et al. 2020; red curve in all plots): (a) skin temperature from ERA5; (b) downwelling SW flux from ERA5; (c) downwelling LW flux from ERA5; (d) downwelling SW flux from CERES SYN1deg; (e) downwelling LW flux from CERES SYN1deg. The shaded region indicates the WAIS January 2016 melt event period (Nicolas et al. 2017). One hour of surface radiometric data is missing on 10 December 2015, but the data are continuous afterward. 

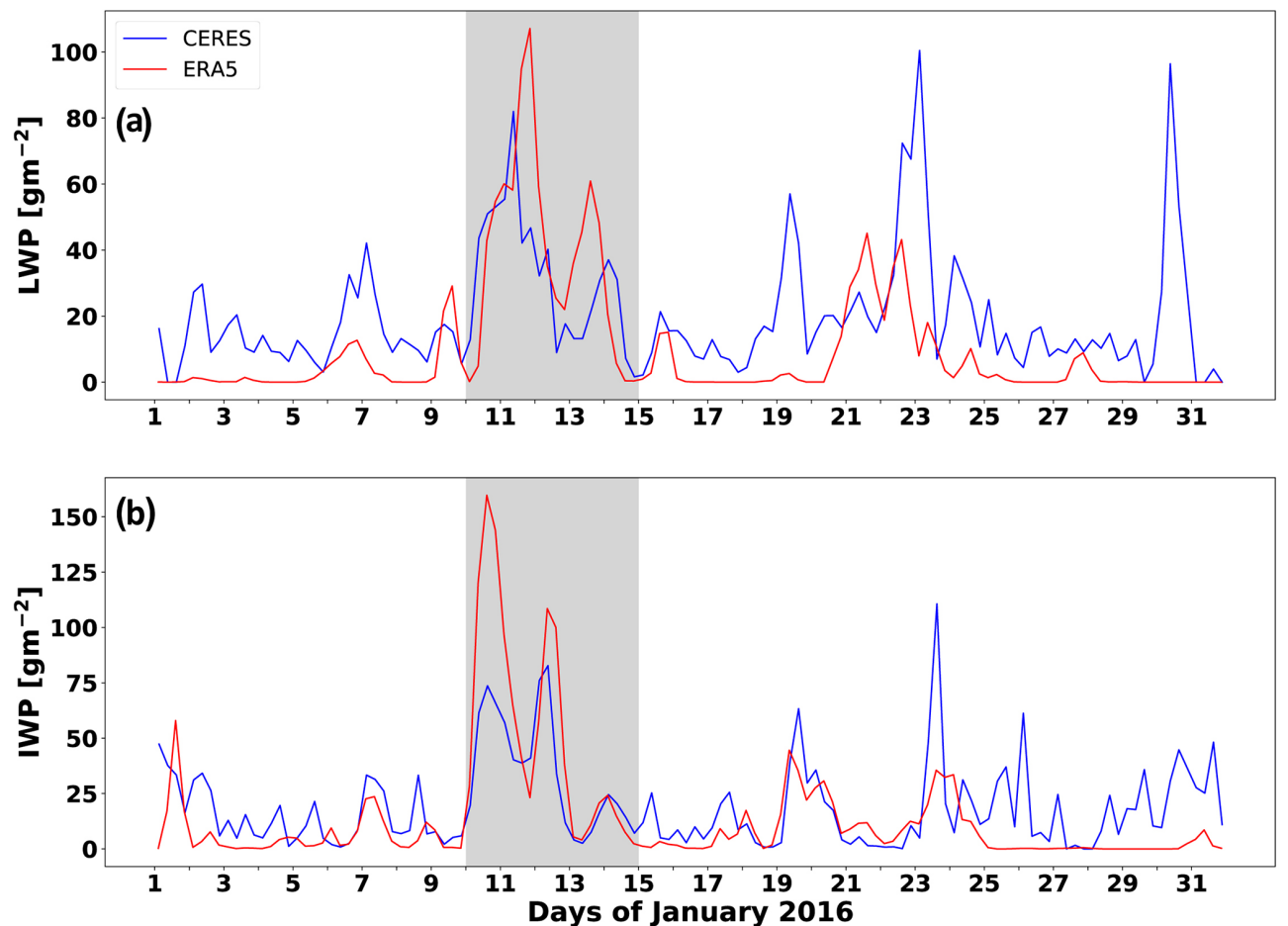

Figure A2. Time series of hourly cloud LWP (a) and IWP (b) from the CERES SYN1deg data product (red) and ERA5 (blue), over the Siple Dome region throughout January 2016. The shaded region denotes the time period of the WAIS large-scale melt event (Nicolas et al. 2017). 

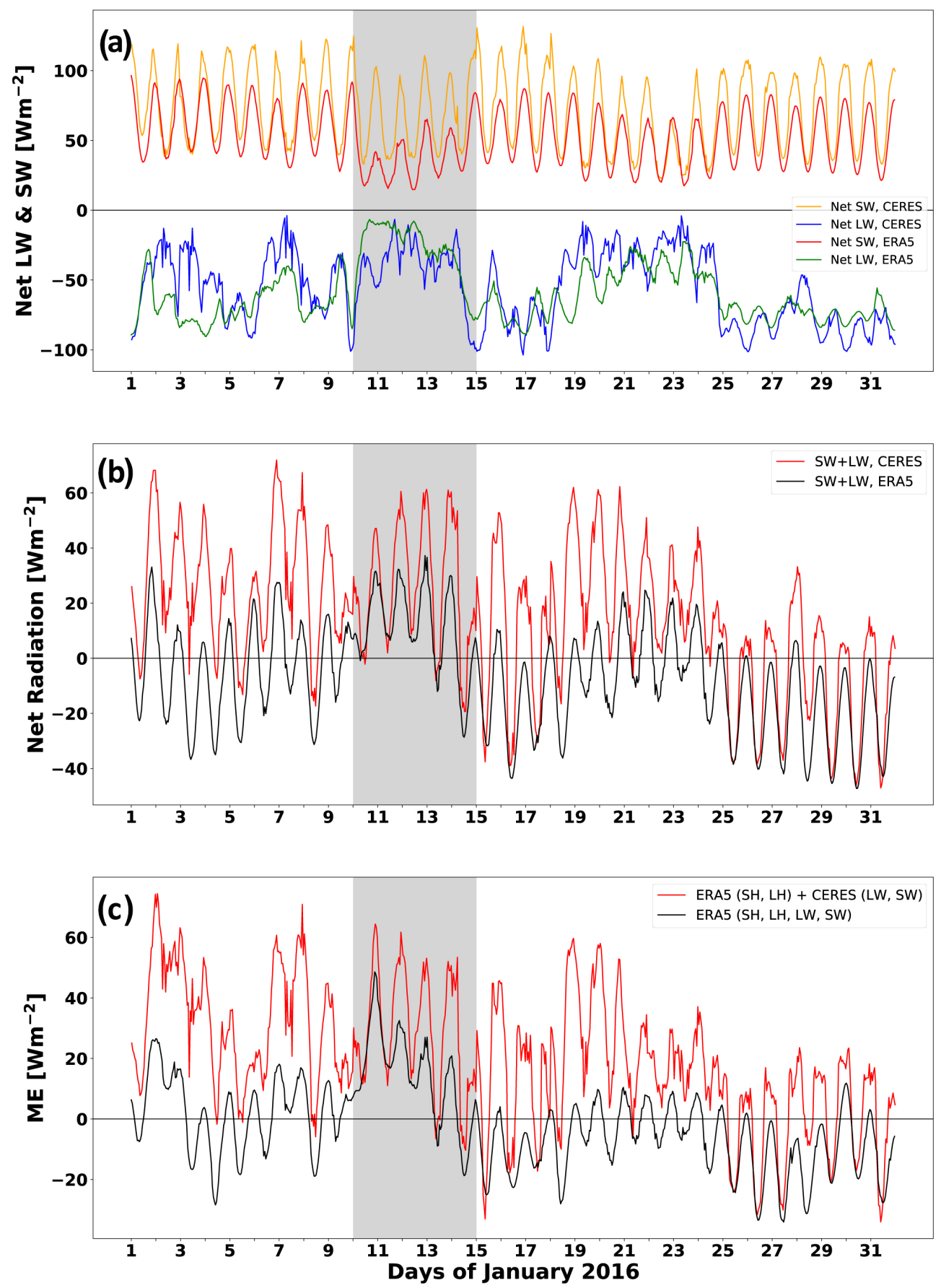

Figure A3. Radiative flux components and alternative estimates of the ME over Siple Dome during January 2016: (a) individual net SW fluxes from ERA5 (red) and CERES SYN1deg data (yellow) and net LW fluxes from ERA5 (green) and CERES SYN1deg data (blue); (b) total net radiative flux from ERA5 (black) and CERES SYN1deg data (red); (c) ME computed entirely from ERA5 (black) and using ERA5 turbulent fluxes but substituting the CERES SYN1deg radiative fluxes (red). 
Appendix B: Examples of satellite passive microwave brightness temperature spatial variability

To illustrate the spatial variability in the surface melt signature, we provide examples of the SSMIS horizontally polarized $19.35 \mathrm{GHz}$ (K-band) brightness temperature $T_{\mathrm{b}}$ measured on the days during each of the case studies when surface melt reached maximum frequency within the bounding region. At Siple Dome on 6 January 2015 (Fig. B1) the extensive surface melting also appears over the eastern edge of the RIS and throughout most of the ASE. On 6 January 2012 , there is considerable spatial variability in $T_{\mathrm{b}}$ over Pine Island Glacier and more uniformity over Thwaites Glacier (Fig. B2), in response to the synoptic situation that normally does not favor surface melt. Similarly, during the late summer melt event of February 2013, there is noticeable spatial variability in $T_{\mathrm{b}}$ over both Pine Island and Thwaites glaciers (Fig. B3), even though this melt event is driven by pronounced thermal blanketing. During the December 2011 synoptic conditions that strongly favor melt, spatial variability in $T_{\mathrm{b}}$ over Pine Island Glacier is still apparent (Fig. B4). Over Siple Dome during late December 2011 (Fig. B5) the measured $T_{\mathrm{b}}$ exhibits spatial uniformity and values $\sim 50 \mathrm{~K}$ smaller than over Thwaites Glacier (Fig. B5). At the RIS location on 23 December 2011, spatial variability in $T_{\mathrm{b}}$ is consistent with a föhn effect, as $T_{\mathrm{b}}$ is above the melt detection threshold close to the Transantarctic Mountains and decreases throughout the bounding region moving away from the mountains.

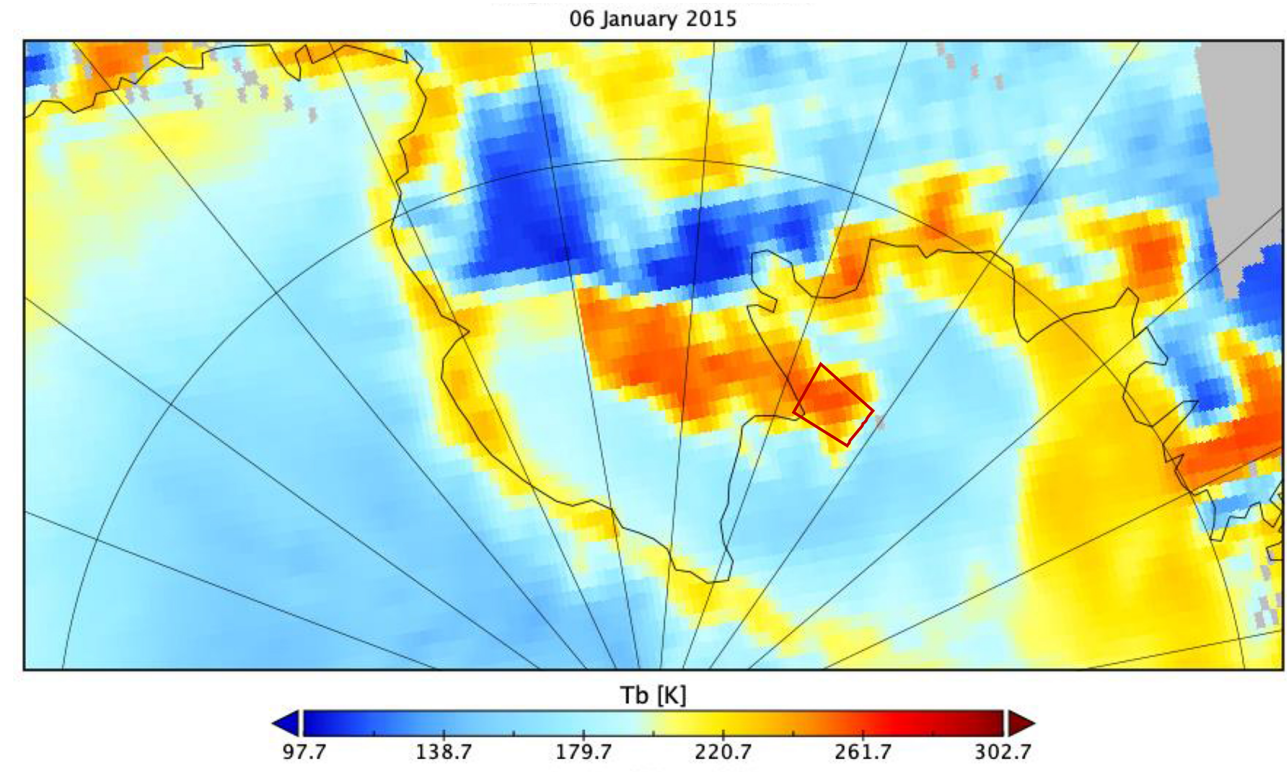

Figure B1. SSMIS horizontally polarized $19.35 \mathrm{GHz}$ brightness temperature over West Antarctica and the RIS on 6 January 2015, with the red box denoting the Siple Dome bounding region used in the case studies. 


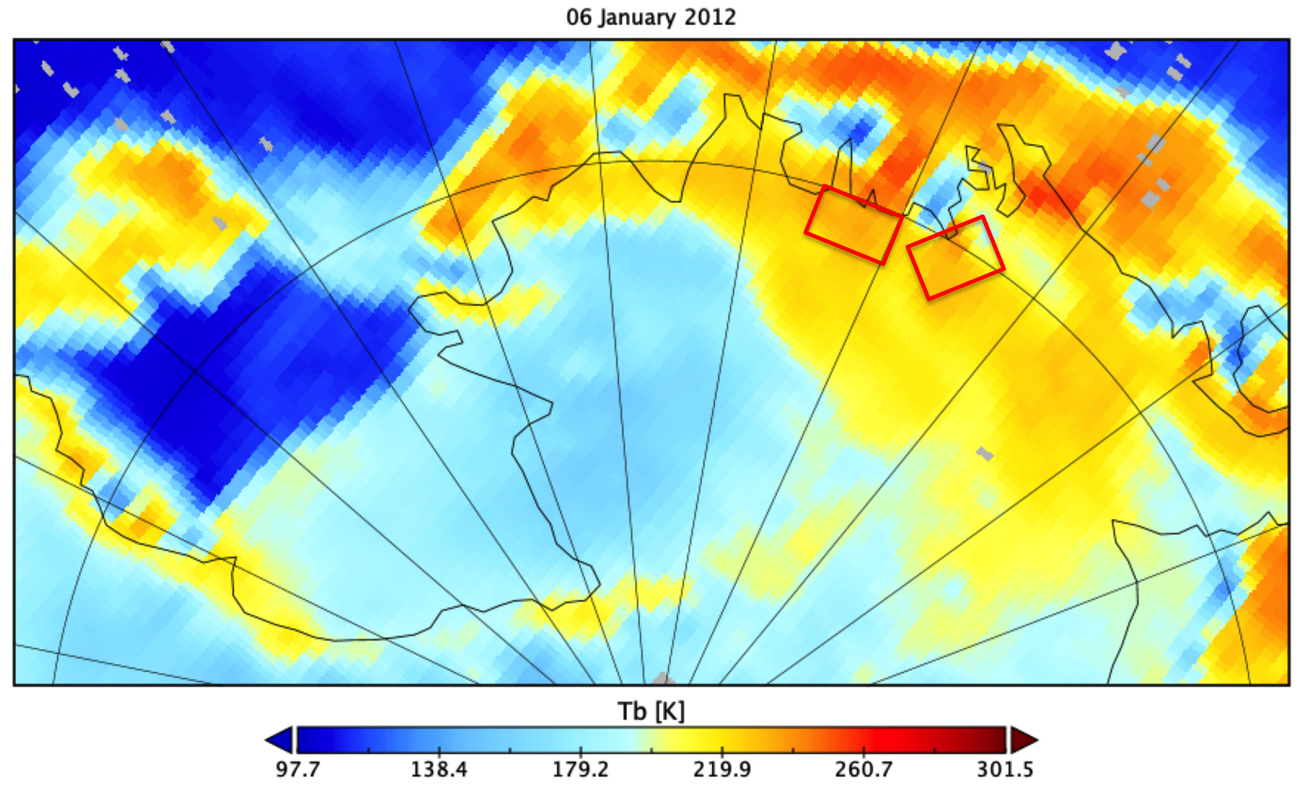

Figure B2. SSMIS horizontally polarized $19.35 \mathrm{GHz}$ brightness temperature over West Antarctica and the RIS on 6 January 2012, with red boxes denoting the Thwaites Glacier (left) and Pine Island Glacier (right) bounding regions.

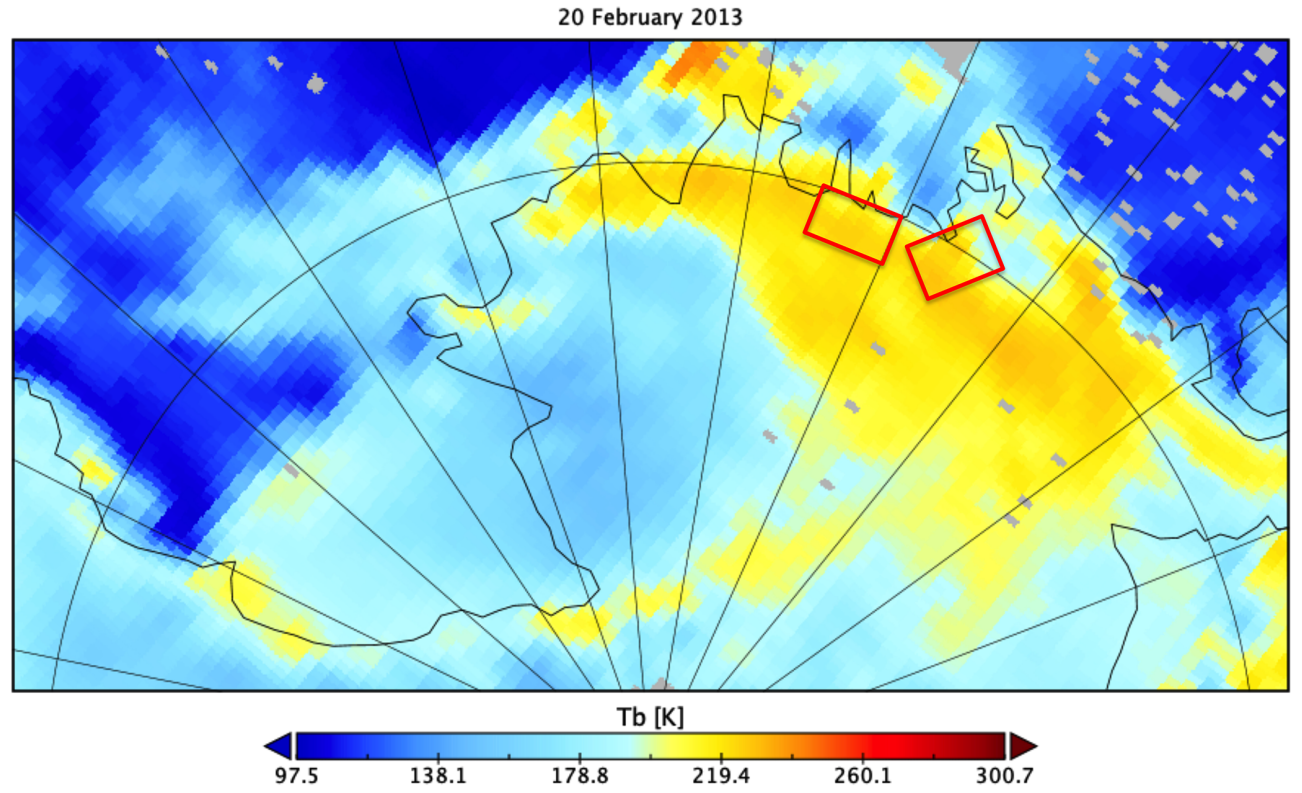

Figure B3. SSMIS horizontally polarized $19.35 \mathrm{GHz}$ brightness temperature over West Antarctica and the RIS on 20 February 2013 , with red boxes denoting the Thwaites Glacier (left) and Pine Island Glacier (right) bounding regions. 


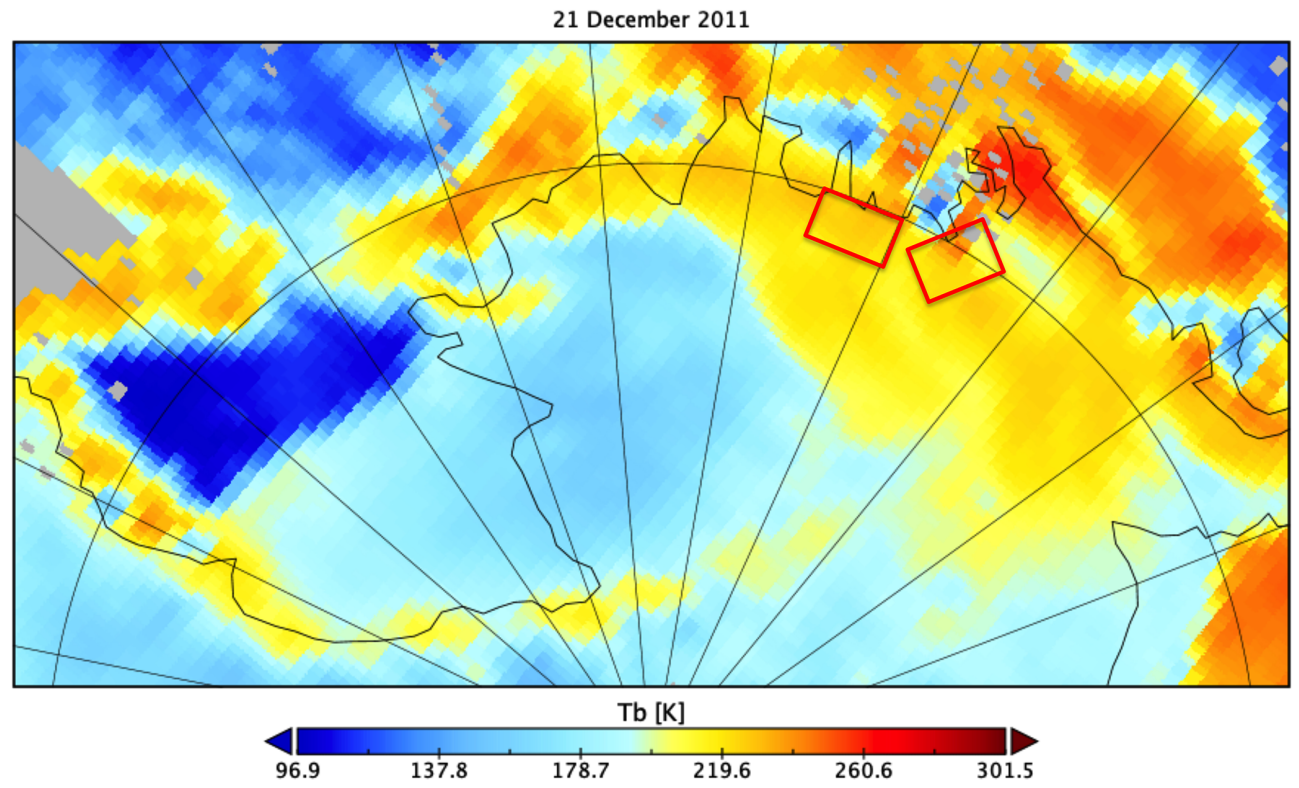

Figure B4. SSMIS horizontally polarized $19.35 \mathrm{GHz}$ brightness temperature over West Antarctica and the RIS on 21 December 2011, with red boxes denoting the Thwaites Glacier (left) and Pine Island Glacier (right) bounding regions.

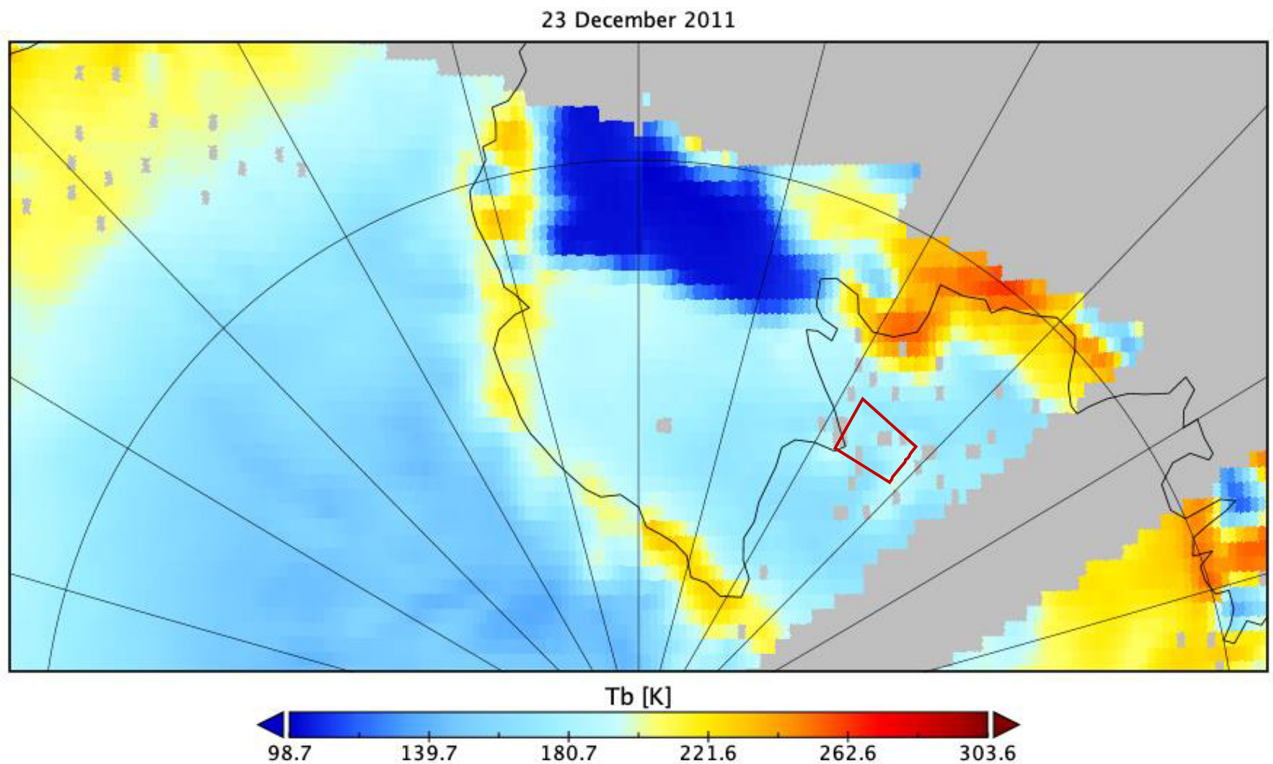

Figure B5. SSMIS horizontally polarized $19.35 \mathrm{GHz}$ brightness temperature over part of West Antarctica and the RIS on 24 December 2011 , with the red box denoting the Siple Dome bounding region. 


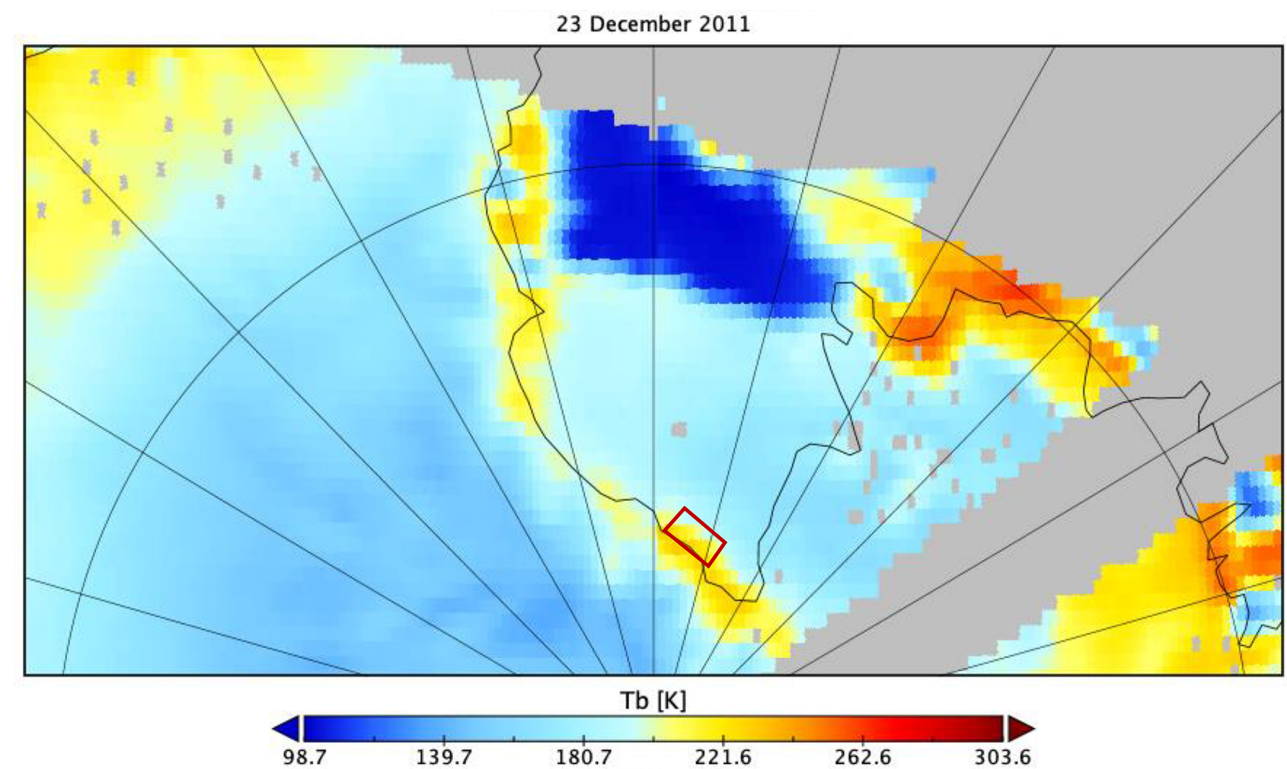

Figure B6. SSMIS horizontally polarized $19.35 \mathrm{GHz}$ brightness temperature over part of West Antarctica and the RIS on 24 December 2011 , with the red box denoting the bounding region containing the Tom and Sabrina AWSs. 
Data availability. ERA5 data were obtained as provided by ECMWF, using the Copernicus Climate Change Service (C3S) Climate Data Store (https://doi.org/10.24381/cds.f17050d7, Hersbach et al., 2019). NASA CERES SYN1deg data were obtained from the NASA Langley Research Center Atmospheric Science Data Center (https://doi.org/10.5067/TERRA+AQUA/CERES/SYN1DEG1HOUR_L3.004A, NASA/LARC/SD/ASDC, 2017). MEaSUREs EASE-Grid 2.0 data were obtained from NSIDC (https://doi.org/10.5067/MEASURES/CRYOSPHERE/NSIDC-

0630.001, Brodzik et al., 2016). AWS and field camp observations are archived at the University of Wisconsin Antarctic Meteorological Research Center (https://amrc.ssec.wisc.edu/data, Lazzara et al., 2012). AWARE broadband radiometric data can be accessed at the ARM Climate Research Facility (https://doi.org/10.5439/1027372, Zhang and Long, 2015).

Author contributions. MLG performed the data analysis and interpretation as part of her master-of-science thesis at the Scripps Institution of Oceanography. RCS provided synoptic- and local-scale meteorological analysis. AMV provided the AWARE surface energy balance data analysis and contributed to manuscript preparation. JTML provided interpretation of the surface energy balance in the case studies and contributed to manuscript preparation. ML provided the AWS and field camp data and their interpretation for this work. DL served as thesis advisor for MLG and contributed to manuscript preparation.

Competing interests. The authors declare that they have no conflict of interest.

Disclaimer. Publisher's note: Copernicus Publications remains neutral with regard to jurisdictional claims in published maps and institutional affiliations.

Acknowledgements. We thank Helen A. Fricker and Joel Norris of the Scripps Institution of Oceanography for polar science and remote sensing advice and expertise throughout the course of this research project. We thank Walt Meier of the National Snow and Ice Data Center for assistance with the MEaSUREs EASE-Grid 2.0 data. We thank the three reviewers for numerous suggestions to improve the content and presentation of the paper.

Financial support. Madison L. Ghiz and Dan Lubin were supported by NSF grant OPP-1744954 and US Department of Energy grant DE-SC0017981. Andrew M. Vogelmann was supported by DOE ASR under contract DE-SC0012704. Jan T. M. Lenaerts was supported by the National Aeronautics and Space Administration under grant 80NSSC18K1025. Matthew Lazzara was supported by NSF grant OPP-1924730.

Review statement. This paper was edited by Ruth Mottram and reviewed by Ella Gilbert and two anonymous referees.
Financial support. This research has been supported by the United States National Science Foundation (grant nos. OPP-1744954 and OPP-1924730), the United States Department of Energy (grant nos. DE-SC0017981 and DE-SC0012704), and the National Aeronautics and Space Administration, Science Mission Directorate (grant no. 80NSSC18K1025).

\section{References}

Adusumilli, S., Fricker, H. A., Medley, B., Padman, L., and Siegfried, M. R.: Interannual variations in meltwater input to the Southern Ocean from Antarctic ice shelves, Nat. Geosci., 13, 616-620, https://doi.org/10.1038/s41561-020-0616-z, 2020.

Alley, R. B., Anandakrishnan, S., Christianson, K., Horgan, H. J., Muto, A., Parizek, B. R., Pollard, D., and Walker, R. T.: Oceanic forcing of ice-sheet retreat: West Antarctica and more, Annu. Rev. Earth Pl. Sc., 43, 207-231, https://doi.org/10.1146/annurevearth-060614-105344, 2015.

Bell, R. E., Chu, W., Kingslake, J., Das, I., Tedesco, M., Tinto, K. J., Zappa, C. J., Frezzotti, M., Boghosian, A., and Lee, W. S.: Antarctic ice shelf potentially stabilized by export of meltwater in surface river, Nature, 544, 344-351, https://doi.org/10.1038/nature22048, 2017.

Bell, R. E., Banwell, A. F., Trusel, L. D., and Kingslake, J.: Antarctic surface hydrology and impacts on icesheet mass balance, Nat. Clim. Change, 8, 1044-1052, https://doi.org/10.1038/s41558-018-0326-3, 2018.

Bennartz, R., Shupe, M. D., Turner, D. D., Walden, V. P., Steffen, K., Cox, C. J., Kulie, M. S., Miller, N. B., and Pettersen, C.: July 2012 Greenland melt extent enhanced by low-level liquid clouds, Nature, 496, 83-86, https://doi.org/10.1038/nature12002, 2013.

Brodzik, M. J., Long, D. G., Hardman, M. A., Paget, A., and Armstrong, R.: MEsSUREs Calibrated Enhanced-Resolution Passive Microwave Daily EASE-Grid 2.0 Brightness Temperature ESDR, Version 1, National Snow and Ice Data Center Distributed Active Archive Center [data set], Boulder, Colorado, USA, https://doi.org/10.5067/MEASURES/CRYOSPHERE/NSIDC0630.001, 2016, Updated 2020.

Bromwich, D. H., Nicolas, J. P., Hines, K. M., Kay, J. E., Key, E. L., Lazzara, M. A., Lubin, D., McFarquhar, G. M., Gorodetskaya, I. V., Grosvenor, D. P., Lachlan-Cope, T., and van Lipzig, N. P. M.: Tropospheric clouds in Antarctica, Rev. Geophys., 50, RG1004, https://doi.org/10.1029/2011RG000363, 2012.

Bromwich, D. H., Nicolas, J. P., Monaghan, A. J., Lazzara, M. A., Keller, L. M., Weidner, G. A., and Wilson, A. B.: Central West Antarctica among the most rapidly warming regions on Earth, Nat. Geosci., 6, 139-145, https://doi.org/10.1038/NGEO2016, 2013.

Chylek, P., Robinson, S., Dubey, M. K., King, M. D., Fu, Q., and Clodius, W. B.: Comparison of near-infrared and thermal infrared cloud phase detections, J. Geophys. Res., 111, D20203, https://doi.org/10.1029/2006JD007140, 2006.

Clem, K. R., Renwick, J. A., and McGregor, J.: Large-scale forcing of the Amundsen Sea Low and its influence on sea ice and West Antarctic temperature, J. Climate, 30, 8405-8423, https://doi.org/10.1175/JCLI-D-16-0891.1, 2017.

Das, S. B. and Alley, R. B.: Characterization and formation of melt layers in polar snow: Observations and ex- 
periments from West Antarctica, J. Glaciol., 51, 307-312, https://doi.org/10.3189/172756505781829395,2005.

Das, S. B. and Alley, R. B.: Rise in frequency of surface melting at Siple Dome through the Holocene: Evidence for increasing marine influence on the climate of West Antarctica, J. Geophys. Res., 113, D02112, https://doi.org/10.1029/2007JD008790, 2008.

Datta, R. T., Tedesco, M., Fettweis, X., Agosta, C., Lhermite, S., Lenaerts, J. T. M., and Wever, N.: The effect of Foehn-induced surface melt on firn evolution over the northeast Antarctic Peninsula, Geophys. Res. Lett., 46, 3822-3831, https://doi.org/10.1029/2018GL080845, 2019.

Deb, P., Orr, A., Bromwich, D. H., Nicolas, J. P., Turner, J., and Hosking, J. S.: Summer drivers of atmospheric variability affecting ice shelf thinning in the Amundsen Sea Embayment, West Antarctica, Geophys. Res. Lett., 45, 4124-4133, https://doi.org/10.1029/2018GL077092, 2018.

DeConto, R. M. and Pollard, D.: Contribution of Antarctica to past and future sea-level rise, Nature, 531, 591-597, https://doi.org/10.1038/nature17145, 2016.

Dee, D., Uppala, S. M., Simmons, A. J., Berrisford, P., Poli, P., Kobayashi, S., Andrae, U., Balmaseda, M. A., Balsamo, G., Bauer, P., Bechtold, P., Beljaars, A. C. M., van de Berg, L., Bidlot, J., Bormann, N., Delsol, C., Dragani, R., Fuentes, M., Geers, A. J., Haimberger, L., Healy S. B., Hersbach, H., Hólm, E. V., Isaksen, L., Kållberg, P., Köhler, M., Matricardi, M., McNally, A. P., Monge-Sanz, B. M., Morcrette, J.-J., Park, B.-K., Peubey, C., de Rosnay, P., Tavolato, C., Thépaut, J.-N., and Vitart, F.: The ERA-Interim reanalysis: Configuration and performance of the data assimilation system, Q. J. Roy. Meteor. Soc., 137, 553-597, https://doi.org/10.1002/qj.828, 2011.

Donat-Magnin, M., Jourdain, N. C., Gallée, H., Amory, C., Kittel, C., Fettweis, X., Wille, J. D., Favier, V., Drira, A., and Agosta, C.: Interannual variability of summer surface mass balance and surface melting in the Amundsen sector, West Antarctica, The Cryosphere, 14, 229-249, https://doi.org/10.5194/tc14-229-2020, 2020.

Dreschel, S. and Mayr, G. J.: Objective forecasting of foehn winds for a subgrid-scale alpine valley, Weather Forecast., 23, 205-218, https://doi.org/10.1175/2007WAF2006021.1, 2008.

Dutra, E., Balsamo, G., Viterbo, P., Miranda, P. M. A., Beljaars, A., Schär, C. and Elder, K.: An improved snow scheme for the ECMWF Land Surface Model: Description and offline validation, J. Hydrometeorol., 11, 899-915, https://doi.org/10.1175/2010JHM1249.1, 2010.

Elvidge, A. D. and Renfrew, I. A.: The Causes of Foehn Warming in the Lee of Mountains, B. Am. Meteorol. Soc., 97, 455-466, https://doi.org/10.1175/BAMS-D-14-00194.1, 2016.

Elvidge, A. D., Renfrew, I. A., King, J. C., Orr, A., Lachlan-Cope, T. A., Weeks, M., and Gray, S. L.: Foehn jets over the Larsen C Ice Shelf, Antarctica, Q. J. Roy. Meteor. Soc., 141, 698-713, https://doi.org/10.1002/qj2382, 2015.

Elvidge, A. D., Kuipers Munneke, P., King, J. C., Renfrew, I. A., and Gilbert, E: Atmospheric drivers of melt on Larsen C Ice Shelf: Surface energy budget regimes and the impact of foehn, J. Geophys. Res., 125, e2020JD032463, https://doi.org/10.1029/2020JD032463, 2020.

Fisher, A. T., Mankoff, K. D., Tulaczyk, S. M., Tyler, S. W., and Foley, N.: High geothermal heat flux measured below the
West Antarctic Ice Sheet, Science Advvances, 1, e1500093, https://doi.org/10.1126/sciadv.1500093, 2015.

Fürst, J. J., Durand, G., Gillet-Chaulet, F., Tavard, L. Ranki, M., Braun, M., and Gagliardini, O.: The safety band of Antarctic ice shelves, Nat. Clim. Change, 6, 479-482, https://doi.org/10.1038/NCLIMATE2912, 2016.

Gilbert, E., Orr, A., King, J. C., Renfrew, I. A., LachlanCope, T., Field, P. F., and Boutle, I. A.: Summertime cloud phase strongly influences surface melting on the Larsen C Ice Shelf, Antarctica, Q. J. Roy. Meteor. Soc., 146, 1575-1589, https://doi.org/10.1002/qj.3753, 2020.

Glasser, N. F. and Scambos, T. A.: A structural glaciological analysis of the 2002 Larsen B ice shelf collapse, J. Glaciol., 54, 3-16, 2008.

Haran, T., Bohlander, J., Scambos, T., Painter, T., and Fahnestock, M.: MODIS Mosaic of Antarctica 2008-2009 (MOA2009) Image Map, West Antarctica, National Snow and Ice Data Center, Boulder, Colorado, USA, https://doi.org/10.7265/N5ZK5DM5, 2014.

Hersbach, H., Bell, B., Berrisford, P., Biavati, G., Horányi, A., Muñoz Sabater, J., Nicolas, J., Peubey, C., Radu, R., Rozum, I., Schepers, D., Simmons, A., Soci, C., Dee, D., and Thépaut, J.N.: ERA5 monthly averaged data on single levels from 1979 to present, Copernicus Climate Change Service (C3S) Climate Data Store (CDS) [data set], https://doi.org/10.24381/cds.f17050d7, 2019.

Hersbach, H., Bell, B., Berrisford, P., Hirahara, S., Horányi, A., Muñoz-Sabater, J., Nicolas, J., Peubey, C., Radu, R., Schepers, D., Simmons, A., Soci, C., Abdalla, S., Abellan, X., Balsamo, G., Bechtold, P., Biavati, G., Bidlot, J., Bonavita, M., De Chiara, G., Dahlgren, P., Dee, D., Diamantakis, M., Dragani, R., Flemming, J., Forbes, R., Fuentes, M., Geer, A., Haimberger, L. Healy, S., Hogan, R. J., Hólm, E., Janisková, M., Keeley, S., Laloyaux, P., Lopez, P., Vamborg, C., Villaume, S., and Thépaut, J.-N.: The ERA5 global reanalysis, Q. J. Roy. Meteorol. Soc, 146, 19992049, https://doi.org/10.1002/qj.3803, 2020.

Hines, K. M., Bromwich, D. H., Wang, S.-H., Silber, I., Verlinde, J., and Lubin, D.: Microphysics of summer clouds in central West Antarctica simulated by the Polar Weather Research and Forecasting Model (WRF) and the Antarctic Mesoscale Prediction System (AMPS), Atmos. Chem. Phys., 19, 12431-12454, https://doi.org/10.5194/acp-19-12431-2019, 2019.

Joughin, I., Smith, B. E., and Medley, B.: Marine ice sheet collapse potentially under way for the Thwaites Glacier Basin, West Antarctica, Science, 344, 735-738, 2014.

Khanal, S. and Wang, Z.: Uncertainties in MODIS-based cloud liquid water path retrievals at high latitudes due to mixed-phase clouds and cloud top height inhomogeneity, J. Geophys. Res., 123, 11154-11172, https://doi.org/10.1029/2018JD028558, 2018.

King, J. C., Kirchgaessner, A., Bevan, S., Elvidge, A. D., Kuipers Munneke, P., Luckman, A., Orr, A., Renfrew, I. A., and van den Broeke, M. R.: The impact of fohn winds on surface energy balance during the 2010-2011 melt season over Larsen C Ice Shelf, Antarctica, J. Geophys. Res., 122, 12062-12076, https://doi.org/10.1002/2017JD026809, 2017.

Kingslake, J., Ely, J. C., Das, I., and Bell, R.: Widespread movement of meltwater onto and across Antarctic ice shelves, Nature, 544, 349-352, https://doi.org/10.1038/nature22049, 2017. 
Kuipers Munneke, P., Picard, G., van den Broeke, M. R., Lenaerts, J. T. M., and van Meijgaard, E.: Insignificant change in Antarctic snowmelt volume since 1979, Geophys. Res. Lett., 39, L01501, https://doi.org/10.1029/2011GL050207, 2012a.

Kuipers Munneke, P., van den Broeke, M. R., King, J. C., Gray, T., and Reijmer, C. H.: Near-surface climate and surface energy budget of Larsen C ice shelf, Antarctic Peninsula, The Cryosphere, 6, 353-363, https://doi.org/10.5194/tc-6-353-2012, 2012b.

Kuipers Munneke, P., Luckman, A. J., Bevan, S. L., Smeets, C. J. P. P., Gilbert, E., van den Broeke, M. R., Wang, W., Zender, C., Hubbard, B., Ashmore, D., Orr, A., King, J. C., and Kulessa, B.: Intense winter surface melt on an Antarctic ice shelf, Geophys. Res. Lett., 45, 7615-7623, https://doi.org/10.1029/2018GL077899, 2018.

Lazzara, M. A., Weidner, G. A., Keller, L. M., Thom, J. E., and Cassano, J. J.: Antarctic automatic weather station program: 30 years of polar observations, B. Am. Meteorol. Soc., 93, 15191537, https://doi.org/10.1175/BAMS-D-11-00015.1, 2012 (data available at: https://amrc.ssec.wisc.edu/data, last access: 30 April 2021).

Lenaerts, J. T. M., Van Tricht, K., Lhermite, S., and L'Ecuyer, T. S.: Polar clouds and radiation in satellite observations, reanalyses, and climate models, Geophys. Res. Lett., 44, 3355-3364, https://doi.org/10.1002/2016GL072242, 2017.

Lenaerts, J. T. M., Ligtenberg, S. R. M., Medley, B., Van De Berg, J. J., Konrad, H., Nicolas, J. P., Van Wessem, J. M., Trusel, L. D., Mulvaney, R., Tuckwell, R. J., Hogg, A. E., and Thomas, E. R.: Climate and surface mass balance of coastal West Antarctica resolved by regional climate modeling, Ann. Glaciol., 59, 29-41, https://doi.org/10.1017/aog.2017.42, 2018.

Lhermitte, S., Sun, S., Shuman, C., Wouters, B. Pattyn, F., Wuite, J., Berthier, E., and Nagler, T: Damage accelerates ice shelf instability and mass loss in Amundsen Sea Embayment, P. Natl. Acad. Sci. USA, 117, 24735-24741, https://doi.org/10.1073/pnas.1912890117, 2020.

Lubin, D., Zhang, D., Silber, I., Scott, R. C., Kalogeras, P., Battaglia, A., Bromwich, D. H., Cadeddu, M., Eloranta, E., Fridlind, A., Frossard, A., Hines, K. M., Kneifel, S., Leaitch, W. R., Lin, W., Nicolas, J., Powers, H., Quinn, P. K., Rowe, P., Russell, L. M., Sharma, S., Verlinde, J., and Vogelmann, A. M.: AWARE: The Atmospheric Radiation Measurement (ARM) West Antarctic Radiation Experiment, B. Am. Meteorol. Soc., 101, E1069-E1091, https://doi.org/10.1175/BAMS-D-180278.1, 2020.

Mather, J. H. and Voyles, J. W.: The ARM Climate Research Facility: A review of structure and capabilities, B. Am. Meteorol. Soc., 94, 377-392, https://doi.org/10.1175/BAMS-D-1100218.1, 2013.

Mätzler, C.: Applications of the interaction of microwaves with the natural snow cover, Remote Sensing Reviews, 2, 259-387, https://doi.org/10.1080/02757258709532086, 1987.

Mouginot, J., Rignot, E., Bjork, A. A., van den Broeke, M., Millan, R., Morlighem, M., Noël, B., Scheuchl, B., and Wood, M.: Forty-six years of Greenland Ice Sheet mass balance from 1972-2018, P. Natl. Acad. Sci. USA, 116, 9239-9244, https://doi.org/10.1073/pnas.1904242116, 2019.

NASA/LARC/SD/ASDC: CERES and GEO-Enhanced TOA, Within-Atmosphere and Surface Fluxes, Clouds and Aerosols 1-Hourly Terra-Aqua Edition4A,
NASA Atmospheric Science Data Center [data set], https://doi.org/10.5067/TERRA+AQUA/CERES/SYN1DEG1HOUR_L3.004A, 2017.

Nicolas, J. P and Bromwich, D. H.: Climate of West Antarctica and influence of marine air intrusions, J. Climate, 24, 49-67, https://doi.org/10.1175/2010JCLI3522.1, 2011.

Nicolas, J. P., Vogelmann, A. M., Scott, R. C., Wilson, A. B., Cadeddu, M. P., Bromwich, D. H., Verlinde, J., Lubin, D., Russell, L. M., Jenkinson, C., Powers, H. H., Ryczek, M., Stone, G., and Wille, J. D.: January 2016 extensive summer melt in West Antarctica favoured by strong El Niño, Nat. Commun., 8, 15799, https://doi.org/10.1038/ncomms15799, 2017.

Oppenheimer, M.: Global warming and the stability of the West Antarctic Ice Sheet, Nature, 393, 325-332, 1998.

Paolo, F. S., Fricker, H. A., and Padman, L.: Volume loss from Antarctic ice shelves is accelerating, Science, 348, 327-330, https://doi.org/10.1126/science.aaa0940, 2015.

Platnick, S., Pincus, R., Wind, B., King, M. D., Gray, M., and Hubanks, P.: An initial analysis of the pixel-level uncertainties in global MODIS cloud optical thickness and effective particle size retrievals, Proc. SPIE 5652, Passive Optical Remote Sensing of the Atmosphere and Clouds IV, https://doi.org/10.1117/12.578353, 2004.

Platnick, S., Meyer, K. G., King, M. D., Wind, G., Amarasinghe, N., Marchant, B., Arnold, G. T., Zhang, Z., Hubanks, P. A., Holz, R. E., Yang, P., Ridgway, W. L., and Riedi, J.:: The MODIS cloud optical and microphysical products: Collection 6 updates and examples from Terra and Aqua, IEEE T. Geosci. Remote, 55, 502 525, https://doi.org/10.1109/TGRS.2016.2610522, 2017.

Pritchard, H. D., Ligtenberg, S. R. M., Fricker, H. A., Vaughan, D. G., van den Broeke, M. R., and Padman, L.: Antarctic ice-sheet loss driven by basal melting of ice shelves, Nature, 484, 502-505, https://doi.org/10.1038/nature10968, 2012.

Rignot, E., Mouginot, J., Scheuchl, B., van den Broeke, M., van Wessem, M. J., and Morlighem M.: Four decades of Antarctic ice sheet mass balance from 1979-2017, P. Natl. Acad. Sci. USA, 116, 1095-1103, https://doi.org/10.1073/pnas.1812883116, 2019.

Rutan, D. A., Kato, S., Doelling, D. R., Rose, F. G., Nguyen, L. T., Caldwell, T. E., and Loeb N. G.: CERES Synoptic Product: Methodology and validation of surface radiant flux, J. Atmos. Ocean. Tech., 32, 1121-1143, https://doi.org/10.1175/JTECHD-14-00165.1, 2015.

Scambos, T. A., Hulbe, C., and Fahnestock, M.: Climate-induced ice shelf disintegration in the Antarctic Peninsula, AGU Antarct. Res. Ser., 79, 79-92, 2003.

Scambos, T. A., Bohlander, J. A., Shuman, C. A., and Skvarca, P.: Glacier acceleration and thinning after ice shelf collapse in the Larsen B embayment, Antarctica, Geophys. Res. Lett., 31, L18402, https://doi.org/10.1029/2004GL020670, 2004.

Scambos, T. A., Haran, T., Fahnestock, M., Painter, T., and Bohlander, J.: MODIS-based Mosaic of Antarctica (MOA) data sets: Continent-wide surface morphology and snow grain size, Rem. Sens. Environ., 111, 242-257, https://doi.org/10.1016/j.rse.2006.12.020, 2007.

Scambos, T. A., Fricker, H. A., Liu, C.-C., Bohlander, J., Fastook, J., Sargent, A., Massom, R., and Wu, A.-M.: Ice shelf disintegration by plate bending and hydro-fracture: Satellite observations 
and model results of the 2008 Wilkins ice shelf break-ups, Earth Planet. Sc. Lett., 280, 51-60, 2009.

Scott, R. C. and Lubin, D.: Mixed-phase cloud radiative properties over Ross Island: The influence of various synopticscale circulation regimes, J. Geophys. Res., 119, 6702-6723, https://doi.org/10.1002/2013JD021132, 2014.

Scott, R. C. and Lubin, D.: Unique manifestations of mixedphase cloud properties over Ross Island and the Ross Ice Shelf, Antarctica, Geophys. Res. Lett., 43, 2936-2945, https://doi.org/10.1002/2015GL067246, 2016.

Scott, R. C., Lubin, D., Vogelmann, A. M., and Kato, S.: West Antarctic Ice Sheet clouds and radiation budget from NASA A-Train satellites, J. Climate, 30, 6151-6170, https://doi.org/10.1175/JCLI-D-16-0644.1, 2017.

Scott, R. C., Nicolas, J. P., Bromwich, D. H., Norris, J. R., and Lubin, D.: Meteorological drivers and large-scale climate forcing of West Antarctic surface melt, J. Climate, 32, 665-684, https://doi.org/10.1175/JCLI-D-18-0233.1, 2019.

Silber, I., Verlinde, J., Wang, S.-H., Bromwich, D. H., Fridlind, A. M., Cadeddu, M., Eloranta, E. W., and Flynn, C. J.: Cloud influence on ERA5 and AMPS surface downwelling longwave radiation biases in West Antarctica, J. Climate, 32, 7935-7949, https://doi.org/10.1175/JCLI-D-19-0149.1, 2019.

Steig, E. J., Schneider, D. P., Rutherford, S. D., Mann, M. E., Comiso, J. C., and Shindell, D. T.: Warming of the Antarctic icesheet surface since the 1957 International Geophysical Year, Nature, 457, 459-462, https://doi.org/10.1038/nature07669, 2009.

Suzuki, K., Yamanouchi, T., Kawamura, K., and Motoyama, H.: The spatial and seasonal distributions of air-transport origins to the Antarctic based on 5-day backward trajectory analysis, Polar Sci., 7, 205-213, https://doi.org/10.1016j.polar.2013.08.001, 2013.

Tedesco, M.: Assessment and development of snowmelt retrieval algorithms over Antarctica from K-band spaceborne brightness temperature (1979-2008), Rem. Sens. Environ., 113, 979-997, 2009.

Tompkins, A. M., Gierens, K., and Rädel, G.: Ice supersaturation in the ECMWF integrated forecast system, Q. J. Roy. Meteor. Soc., 133, 53-63, https://doi.org/10.1002/qj.14, 2007.

Torinesi, O., Fily, M., and Genthon, C.: Variability and trends of the summer melt period of Antarctic ice margins since 1980 from microwave sensors, J. Climate, 16, 1047-1060, 2003.

Trusel, L. D., Frey, K. E., Das, S. B., Kuipers Munneke, P., and van den Broeke, M. R.: Satellite-based estimates of Antarctic surface meltwater fluxes, Geophys. Res. Lett., 40, 6148-6153, https://doi.org/10.1002/2013GL058138, 2013.

Turner, J., Phillips, T., Hosking, J. S., Marshall, G. J., and Orr, A.: The Amundsen Sea low, Int. J. Climatol., 33, 1818-1829, https://doi.org/10.1002/joc.3558, 2013.

van As, D., van den Broeke, M., Reijmer, C., and van de Wal, R.: The summer surface energy balance of the high Antarctic Plateau, Bound.-Lay. Meteorol., 115, 289-317, https://doi.org/10.1007/s10546-004-4631-1, 2005. van den Broeke, M.: Strong surface melting preceded collapse of Antarctic Peninsula ice shelf, Geophys. Res. Lett., 32, L12815, https://doi.org/10.1029/2005GL023247, 2005.

Van Tricht, K., Lhermite, S., Lenaerts, J. T. M., Gorodetskaya, I. V., L'Ecuyer, T. S., Noël, B., van den Broeke, M. R., Turner, D. D., and van Lipzig, N. P. M.: Clouds enhance Greenland Ice Sheet meltwater runoff, Nat. Commun., 7, 10266, https://doi.org/10.1038/ncomms10266, 2016.

van Wessem, J. M., Reijmer, C. H., Lenaerts, J. T. M., van de Berg, W. J., van den Broeke, M. R., and van Meijgaard, E.: Updated cloud physics in a regional atmospheric climate model improves the modelled surface energy balance of Antarctica, The Cryosphere, 8, 125-135, https://doi.org/10.5194/tc-8-125-2014, 2014.

van Wessem, J. M., van de Berg, W. J., Noël, B. P. Y., van Meijgaard, E., Amory, C., Birnbaum, G., Jakobs, C. L., Krüger, K., Lenaerts, J. T. M., Lhermitte, S., Ligtenberg, S. R. M., Medley, B., Reijmer, C. H., van Tricht, K., Trusel, L. D., van Ulft, L. H., Wouters, B., Wuite, J., and van den Broeke, M. R.: Modelling the climate and surface mass balance of polar ice sheets using RACMO2 Part 2: Antarctica (1979-2016), The Cryosphere, 12, 1479-1498, https://doi.org/10.5194/tc-12-1479-2018, 2018.

Weertman, J.: Stability of the junction of an ice sheet and an ice shelf, J. Glaciol., 13, 3-11, 1974.

Wille, J. D., Favier, V., Dufour, A., Gorodetskaya, I. V., Turner, J., Agosta, C., and Codron, F.: West Antarctic surface melt triggered by atmospheric rivers, Nat. Geosci., 12, 911-916, https://doi.org/10.1038/s41561-019-0460-1, 2019.

Wilson, A., Scott, R. C., Cadeddu, M. P., Ghate, V., and Lubin, D.: Cloud optical properties over West Antarctica from shortwave spectroradiometer measurements during AWARE, J. Geophys. Res., 123, 9559-9570, https://doi.org/10.1029/2018JD028347, 2018.

Wilson, A., Scott, R. C., Cadeddu, M. P., Ghate, V., and Lubin, D: Cloud optical properties over West Antarctica from shortwave spectroradiometer measurements during AWARE, J. Geophys. Res., 123, 9559-9570, https://doi.org/10.1029/2018JD028347, 2018.

Zhang, D. and Long, C.: Data quality assessment for ARM Radiation Data (QCRAD1LONG), Atmospheric Radiation Measurement (ARM) user facility [data set], https://doi.org/10.5439/1027372, 2015.

Zou, X., Bromwich, D. H., Nicolas, J. P., Montenegro, A., and Wang, S.-H.: West Antarctic surface melt event of January 2016 facilitated by föhn warming, Q. J. Roy. Meteor. Soc., 145, 687704, https://doi.org/10.1002/qj3460, 2018.

Zwally, H. J. and Feigles, S.: Extent and duration of Antarctic surface melting, J. Glaciol., 40, 463-476, 1994. 